\title{
Cyclic Linearization of Syntactic Structure
}

\author{
DANNY FOX and DAVID PESETSKY
}

\section{Abstract}

This paper proposes an architecture for the mapping between syntax and phonology - in particular, that aspect of phonology that determines the linear ordering of words. We propose that linearization is restricted in two key ways. (1) the relative ordering of words is fixed at the end of each phase, or "Spell-out domain"; and (2) ordering established in an earlier phase may not be revised or contradicted in a later phase. As a consequence, overt extraction out of a phase P may apply only if the result leaves unchanged the precedence relations established in $P$. We argue first that this architecture ("cyclic linearization") gives us a means of understanding the reasons for successive-cyclic movement. We then turn our attention to more specific predictions of the proposal: in particular, the effects of Holmberg's Generalization on Scandinavian Object Shift; and also the Inverse Holmberg Effects found in Scandinavian "Quantifier Movement" constructions (Rögnvaldsson (1987); Jónsson (1996); Svenonius (2000)) and in Korean scrambling configurations (Ko (2003, 2004)). The cyclic linearization proposal makes predictions that cross-cut the details of particular syntactic configurations. For example, whether an apparent case of verb fronting results from $V$-to- $C$ movement or from "remnant movement" of a VP whose complements have been removed by other processes, the verb should still be required to precede its complements after fronting if it preceded them before fronting according to an ordering established at an earlier phase. We argue that "cross-construction" consistency of this sort is in fact found.

\section{Introduction 1}

This paper proposes an architecture for the mapping between syntax and phonology - in particular, that aspect of phonology that determines

1 The present paper is the first installment in a larger project (Fox and Pesetsky (in prep.)). The inspiration for this work can be traced to a conversation with John 
ordering. In Fox and Pesetsky (in prep.), we will argue that this architecture, when combined with a general theory of syntactic domains ("phases"), provides a new understanding of a variety of phenomena that have received diverse accounts in the literature. This shorter paper focuses on two processes, both drawn from Scandinavian: the familiar process of Object Shift and the less well-known process of Quantifier Movement. We will argue that constraints on these operations can be seen as instances of the same property of grammar that explains the fact that movement is local and successive cyclic. We begin by sketching a model in which locality and successive cyclicity are consequences of the architecture that we propose, rather than specific facts about movement itself. We next present our proposal in somewhat greater detail, and show how it can account for a wide range of apparent limitations on movement - in particular, superficially contradictory restrictions on Object Shift and Quantifier Movement. The restrictions on Object Shift include those grouped under the rubric of Holmberg's Generalization, which Quantifier Movement does not seem to obey. We will argue that Quantifier Movement instead obeys a near mirror-image of Holmberg's Generalization (an "Inverse Holmberg Effect"), but that both Holmberg's Generalization and its mirror image are expected if our proposed architecture is correct.

Our discussion will be for the most part informal, but we will conclude by offering a more formal implementation of our proposals. This

Frampton, and to a fruitful additional meeting with John Frampton and Sam Guttmann. We are grateful to both of them, and also to the students and visitors who attended our Spring 2003 seminar at MIT, where much of this work was first presented and developed. We also want to express our gratitude for the contributions to our work of Elena Anagnostopoulou, Jonathan Bobaljik, Misi Brody, Noam Chomsky, Anders Holmberg, Sabine Iatridou, Kyle Johnson, Noriko Kawasaki, Heejeong Ko, Alec Marantz, Andrew Nevins, Øystein Nilsen, Jon Nissenbaum, Christer Platzack, Norvin Richards, Joey Sabbagh, Peter Svenonius, Shoichi Takahashi, and Sophia Tapio, among others. We also wish to thank for their comments and questions audiences at Sophia University (Tokyo); Université de Paris VII; Indiana University; Kyoto University (Kaken Ellipsis Workshop); University of Vittoria (Basque Country); University of Milan-Bicocca; the University of Massachusetts/Amherst; the Workshop on Interfaces (Château de la Bretèche); the 2003 LSA Summer Institute (Michigan State University); GLOW 2003 (Lund); and the First North American Syntax Conference (Concordia University, Montreal). 
implementation will belong to a family of possibilities consistent with our overall model. We will leave for the fuller presentation a comparison of these alternatives, along with a range of other empirical consequences.

\section{Successive-cyclicity and linear order}

Much attention has been devoted to movement relations that appear to be long-distance or unbounded. A large body of work has converged on the conclusion that such relations actually represent the result of the compounding of a series of more local relations. For example, the apparent long-distance property of $w h$-movement in a sentence such as (1) seems to be a consequence of a series of shorter movement relations - at least through intermediate specifiers of $\mathrm{CP}$ and specifiers of $\mathrm{VP}^{2}$ as shown in (1):

\section{(1) Successive-cyclic wh-movement}

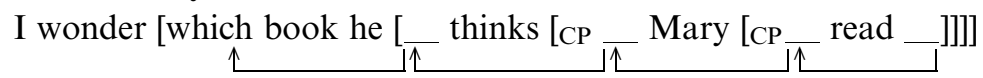

Evidence for the possibility of successive cyclic movement through Spec, CP and Spec,VP includes a variety of reconstruction phenomena (see Barss (1986), Lebeaux (1991) for CP; Fox (1999) for VP) - as well as the possibility of stranding wh-related elements (McCloskey (2000)) and perhaps wh-phrases themselves (McDaniel (1989); Gračanin (2004)) in at least some intermediate Spec, $\mathrm{CP}$ and Spec,VP positions.

Additional evidence supports an even stronger conclusion. If Chomsky (1973) and others are correct in linking island effects to the existence of intermediate landing sites, it must be the case that long-distance movement does not merely permit, but actually requires the use of these intermediate positions. We must then ask why. This question has figured prominently in much discussion over the past quarter century, and a variety of answers have been suggested.

2 To keep the discussion simple, we will not make a distinction between $v \mathrm{P}$ and VP (as argued for by Hale and Keyser (1993) and Hale and Keyser (2002), among others) in the first part of this paper. We return to the $v \mathrm{P} / \mathrm{VP}$ distinction below and in Fox and Pesetsky (in prep.). 
All proposals known to us attribute a special status to particular syntactic domains, variously called "bounding nodes", "barriers" and "phases". Our proposal will not differ in this respect. For now, we will follow Chomsky (2000) in using the term "phase" for the domains in question, to highlight a similarity between our proposal and his, to which we return later. Traditionally, phases play two distinct roles - and it is on this point that our proposal will crucially differ from others, including Chomsky's. On the one hand, a phase is taken to determine an "impenetrable domain" from which movement is generally excluded. On the other hand, it is also taken to determine a specific position as an "escape hatch". The escape hatch provides the one and only legal route for movement out of the phase. Thus, for example, if CP is a phase, it determines that movement out of CP is impossible from any position except Spec,CP - its designated escape hatch. This forces all apparent long-distance movement from CP to be analyzed as involving movement through its escape hatch. More generally, apparent movement from any phase, on traditional accounts, must involve the escape hatch of that phase as an intermediate step.

Our approach will have in common with traditional proposals the requirement that movement from a phase proceeds through certain specific types of positions within that phase. Unlike traditional proposals, however, our approach does not stipulate particular positions that provide escape hatches for movement - nor is there any concept of "escape hatch" built into the theory. "Escape hatch effects" are, if we are correct, an artifact of the role played by phases in linearization of the terminal elements of syntactic structure. These effects are thus a consequence of the mapping between syntax and phonology. ${ }^{3}$

Consider the derivation in (2), in which wh-movement proceeds through intermediate specifiers of VP and CP: ${ }^{4}$

3 For other proposals that relate island effects (and requirements of successive cyclicity) to syntax-phonology interactions, see Pesetsky (1998) (with an antecedent in Perlmutter (1972)); Uriagereka (1999); among others.

4 It is important to our discussion that the intermediate positions indicated in (2) are on the left side of VP and CP. This proposal is independently supported (for CP) by the observations of McCloskey (2000). Our paper as a whole will constitute a sustained argument for this position. See Nissenbaum (2000) for possibly conflicting evidence. 
(2) Successive-cyclic wh-movement through Spec, $C P$ and Spec, $v P$

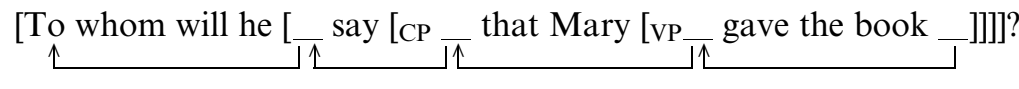

$\begin{array}{llll}4 & 3 & 2 & 1\end{array}$

Let us focus on a particular property of the movements seen in (2). Consider first step 1, which takes place entirely within the lowest VP phase. This step can be seen as "revising" the word order of VP insofar as whmovement to Spec,VP causes the wh-phrase to precede the words gave the book. which it would otherwise follow. Now consider step 2. This step also "revises" word order, causing the wh-phrase to precede the words that Mary which, once more, it would otherwise have followed. Notice, however, that step 2 only revises word order with respect to these words - not with respect to the words contained within the previous phase. The $w h$-phrase preceded the words gave the book at the end of the lowest VP phase, and still precedes them at the end of the next phase.

This type of observation can be repeated for each subsequent step. Thus step 3 revises the order of the wh-phrase with respect to the verb say, but not with respect to the words that Mary gave the book. Likewise, step 4 revises the order of the wh-phrase with respect to the words will he, but not with respect to any of the words dominated by lower phases.

The generalization is clear. Each time the wh-phrase moves, it leaves unchanged its linear order with respect to words dominated by previous phases, but may revise linear order with respect to words introduced in the current phase. We propose that this property of (2) is not a coincidence. As we will argue, if this property did not obtain, the sentence could not be linearized. This proposal will constitute the core of our explanation for the obligatoriness of successive-cyclic movement and will be the key component of our account of Holmberg's Generalization and of Inverse Holmberg Effects. ${ }^{5}$

5 Our account of Holmberg's Generalization has significant properties in common with earlier work that views the phenomenon as a consequence of ordering generalizations that constrain the independent working of syntactic operations, e.g. Sells (2001), Williams (2003); Müller (2000); Kathol (2000). Our proposal differs from these works in a number of respects - most crucially in the fact that linearization is established on a phase-by-phase basis. This property of our proposal yields a structural distinction between aspects of linear order that may be affected by a syntactic operation and those 


\section{General proposal}

We assume, with Chomsky (2000, 2001a), that syntactic derivations involve the operations Merge and Move ("remerge"), with the consequence that structure is built from "bottom to top". We also take from Chomsky the suggestion that the mapping between syntax and phonology (Spellout) takes place at various points in the course of the derivation - rather than at a single point, as in traditional models. In this work, we focus on one key aspect of Spell-out: linearization. When Spell-out applies, it is possible that other relations among syntactic units (besides linear order) are established - for example, relations relevant to the determination of phonological phrasing. We will not be discussing these other relations, but will restrict our attention to linear order.

We will use the term Spell-out domain to refer to the constituents that are mapped to phonology by Spell-out. (We return shortly to the relation between the notion Spell-out domain and the notion phase.) The list of Spell-out domains includes at least CP, VP and DP. ${ }^{6}$ Each time the derivation constructs a Spell-out domain D, Spell-out applies, linearizing D. The first time this happens, Spell-out takes D as input and yields straightforwardly a linearization of D. Each time a new Spell-out domain $\mathrm{D}^{\prime}$ is constructed, Spell-out linearizes the new material in $\mathrm{D}^{\prime}$ and adds information about its linearization to the information cumulatively produced by previous applications of Spell-out.

The key property of our proposal that contributes to an account of successive-cyclic movement is the following claim: information about linearization, once established at the end of a given Spell-out domain, is never deleted in the course of a derivation. The sole function of Spell-out is to add information. We will call this monotonicity property of Spellout Order Preservation.

that may not, and consequently allows us to relate Holmberg's Generalization to phenomena such as successive-cyclicity and Inverse Holmberg Effects. See Fox and Pesetsky (in prep.) for more discussion.

6 In Fox and Pesetsky (in prep.), we will have important qualifications about the type of verb-headed phrase that counts as a Spell-out Domain. For now, we continue to use the designation "VP", ignoring the $v \mathrm{P} / \mathrm{VP}$ distinction. We touch on this distinction briefly in section 5 below. See also Sabbagh (2003) for arguments that PP is a Spell-out domain and for a discussion of certain problems concerning the status of DP. 


\subsection{Successive-cyclicity as a consequence of Order Preservation}

Let us examine how Order Preservation might enforce successivecyclicity. Imagine that the phrase to whom in (2) had moved directly to the specifier of the lower $\mathrm{CP}$ - without first stopping in the specifier of $\mathrm{VP}$, as sketched in (3):

(3) Wh-movement skipping Spec,vP - yielding an ordering contradiction

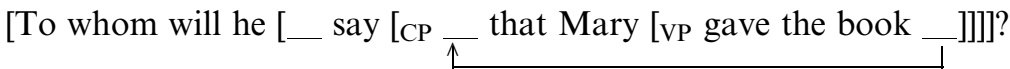

If the proposal above is correct, movement to Spec, CP must follow Spellout of VP, since VP is a Spell-out domain. In English, heads precede their complements, and PP objects follow direct objects. As a consequence, the process of Spell-out applying to VP linearizes elements of VP, as represented informally in (4). The expression "A $<\mathrm{B}$ " should be read (for now) as "A precedes B":

(4) Spell-out applies to VP (non-successive-cyclic derivation)

gave $<$ the book $<$ to whom

After to whom moves to Spec,CP, Spell-out of CP yields the following ordering information - assuming, as is the general case in English, that the specifier of a phrase XP precedes its sister $X^{\prime}$ :

(5) Spell-out applies to CP (non-successive-cyclic derivation)

to whom $<$ that $<$ Mary $<\mathrm{VP}$

The information in (4) and the information in (5) impose conflicting requirements on the phonology. By (4), to whom must be pronounced after the words gave, the and book, but (5) requires to whom to be pronounced before these words (since they are contained in VP). Given Order Preservation, we suggest that it is this phonological problem - this ordering contradiction - that rules out the non-successive-cyclic derivation.

Consider, by contrast, the successive-cyclic derivation in which to whom first moves to Spec, VP before moving on to Spec,CP.

(6) Wh-movement stopping in Spec, $V P$ - avoiding an ordering contradiction

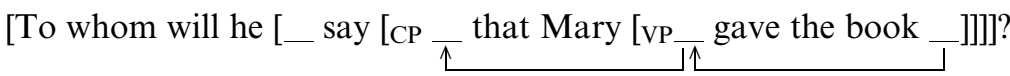

In this derivation, when Spell-out applies to VP, the phrase to whom occupies Spec,VP, and is thus ordered to the left of the words gave the book 
- rather than to the right of these words, as was the case in the nonsuccessive-cyclic derivation above:

(7) Spell-out applies to VP (successive-cyclic derivation)

to whom < gave < the book

Once CP has been built, and to whom has moved to Spec,CP, Spell-out applies to $\mathrm{CP}$ just as it did in the non-successive-cyclic derivation:

(8) Spell-out applies to $\mathbf{C P}$ (successive-cyclic derivation)

to whom $<$ that $<$ Mary $<\mathrm{VP}$

Continuing to read "A $<$ B" as "A precedes B", we can see that the information in (7) and (8) (unlike the information in (4) and (5)) does not yield an ordering contradiction. There is no conflict between the constraints imposed on the phonology by (7), which require that to whom precede the VP elements gave the book, and the constraints imposed by (8), which require that to whom precede the words that Mary in addition to preceding VP elements. The successive-cyclic derivation succeeds where the non-successive-cyclic derivation fails, for exactly the reason discussed at the end of the previous section. When the wh-phrase moved to Spec,CP in the successive-cyclic derivation, it left unchanged its linear order with respect to the words that had been linearized in the previous Spell-out domain, even though new orderings were established with respect to the words that and Mary that were merged in the course of building CP.

An architecture of this sort will in general force successive cyclicity when movement crosses a Spell-out domain boundary. Our proposal does, however, have certain unique features (both conceptual and empirical) which distinguish it from alternative hypotheses about the roots of successive cyclicity. These unique aspects of our proposal will become clear once we have spelled it out in somewhat greater detail. This presentation will still be somewhat informal. A more precise presentation will follow in section 7 .

\subsection{Derivational scenarios}

Suppose a bottom-to-top derivation has created the syntactic domain D in (9), where D is also a Spell-out domain. Assume that the Spell-out operation establishes the ordering statements given in (9). 
(9) Spell-out of D

[D X Y Z]

$$
\text { Ordering: } \quad \begin{aligned}
& \mathbf{X}<\mathbf{Y} \\
& \\
& \mathbf{Y}<\mathbf{Z}
\end{aligned}
$$

Before proceeding, we should comment briefly on the status of the "ordering statements" provided in (9) (and many similar presentations to follow). Throughout most of this paper, the lists of ordering statements will be informal and will generally contain only information relevant to the point being made. Ultimately, we will specify the exact format in which actual ordering statements produced by Spell-out are presented to the phonetic systems. At that point, further questions will arise. For example, does the set of actual ordering statements in a situation such as (9) include a redundant statement such as " $\mathrm{X}<\mathrm{Z}$ '? What are the actual elements mentioned in the ordering statements: phrases? words? combinations of the two? The answer to questions of this sort will turn out to have important consequences, which we will present in a fuller version of this work. For now, however, we can keep the discussion relatively simple by providing only relevant, non-redundant ordering statements in our informal presentations and using conventional abbreviations like "VP" whose exact role in these statements will ultimately demand clarification.

As an initial step towards a more precise formulation of our proposals, let us understand the significance of the symbol " $<$ " as follows:

\section{(10) The relation " $<$ " [first statement]}

An ordering statement of the form $\alpha<\beta$ is understood by PF as meaning that the last element dominated ${ }^{7}$ by $\alpha$ precedes the first element dominated by $\beta$.

A statement of the form "DP $<\mathrm{VP}$ ", for example, means that the last element dominated by DP precedes the first element dominated by VP. For now, we will generally assume that the relevant "elements" are words (although one could also imagine a variant in which the elements relevant to (10) are phonological segments). When presenting actual examples, we

7 "Dominate" throughout this work means "reflexively dominate". This interpretation of the term is important for the case in which $\alpha$ or $\beta$ is a word. 
will indicate, where necessary, the words relevant to the interpretation of "<".

It is also important to specify the way in which movement can affect phonology. Consider a traditional view of movement as an operation that creates a "chain" containing two elements. On this view, one element is new, and constitutes the "head" of the chain. The other element was previously merged, and constitutes a "trace". With this view in mind, we will need to stipulate that Spell-out pays attention only to the head of a chain, and ignores traces. Thus, under a traditional view of movement, the statement of (10) should be modified as follows:

\section{(11) The relation " $<$ " [modified to fit with copy theory of movement]}

An ordering statement of the form $\alpha<\beta$ is understood by PF as meaning that the last element dominated by $\alpha$ and not dominated by a trace precedes the first element dominated by $\beta$ and not dominated by a trace.

In section 7, we will adopt a view of movement as a second merger of a single element rather than a copying procedure that constructs a chain (Blevins (1990); Chomsky (2001a, b); Epstein et al. (1998)). At that point in the discussion, we will no longer need a distinction between traces and non-traces, and will be able to revert to a simpler theory of how PF interprets " $<$ " - essentially the statement in (10), coupled with a notion of "dominates" that is defined for structures in which a single element merges twice.

Of course, the system (under either view of movement) must already "know" what is first and last in $\mathrm{X}$ and $\mathrm{Y}$ in order to interpret statements like " $\mathrm{X}<\mathrm{Y}$ ". How the system acquires this information will also be a topic of discussion in our more formal presentation in section 7. Once again, however, it will be possible to see that the formal clarifications discussed in that section leave our previously discussed results unchanged.

Let us now return to (9). Imagine that after Spell-out applies to D, the syntax merges $\alpha$ with $\mathrm{D}$, yielding (12):

\section{$\alpha$ merges with $D$}

$\alpha$ [D X Y Z]

Consider a situation in which, after merger of $\alpha$, some element in D undergoes leftward movement into the higher Spell-out domain. As our 
discussion of successive-cyclic $w h$-movement made clear, we will want to consider two possible scenarios, depending on whether or not the element that moved out of D previously occupied the left edge of $\mathrm{D}$.

In the first scenario, it is $\mathrm{X}$ that moves leftward, as part of the construction of the next Spell-out domain $\mathrm{D}^{\prime}$. When $\mathrm{D}^{\prime}$ is spelled out, the linearization of $\mathrm{D}^{\prime}$ will add (to the ordering statements from $\mathrm{D}$ ) the new (boldfaced) ordering statements listed in (13):

(13) Scenario 1 (leftward movement from a left-edge position) $\left[\mathrm{D}^{\prime} \ldots \underset{\Lambda}{\mathrm{X}} \alpha\left[\mathrm{D} t_{\mathrm{X}} \mathrm{Y} Z \mathrm{Z}\right]\right]$

$$
\begin{array}{lll}
\text { Ordering: } & \mathbf{X}<\boldsymbol{\alpha} & \mathrm{X}<\mathrm{Y} \\
& \boldsymbol{\alpha}<\mathbf{D} \rightarrow \boldsymbol{\alpha}<\mathbf{Y} & \mathrm{Y}<\mathrm{Z}
\end{array}
$$

As we noted above, " $\mathrm{X}<\alpha$ " means that the last element of $\mathrm{X}$ (not dominated by a trace) precedes the first element of $\alpha$ (not dominated by a trace). Likewise, " $\alpha<\mathrm{D}$ " means that the last relevant element of $\alpha$ precedes the first relevant element of D - in this case, Y (i.e. the first element of $\mathrm{Y}$, if $\mathrm{Y}$ itself is complex). The arrow after " $\alpha<\mathrm{D}$ " shows this consequence of the ordering statement, namely that PF pronounces $\alpha$ before Y. We will not mark such consequences consistently - only when it helps make things clearer.

The key point, as we stressed when discussing successive-cyclic whmovement, is the following. Because $\mathrm{X}$ was at the left edge of D when D underwent Spell-out, the ordering statements added by Spell-out of $D^{\prime}$ are consistent with the ordering statements previously added in D. Leftward movement from the left edge of a Spell-out Domain thus yields no ordering contradictions.

Now consider the alternative scenario, in which an element not at the left edge of $\mathrm{D}$ - for example, $\mathrm{Y}$ - undergoes movement as part of the formation of $\mathrm{D}^{\prime}$. In this scenario, when $\mathrm{D}^{\prime}$ is spelled out, it will include all the ordering statements from $\mathrm{D}$ as well as the new ordering statements in (14):

(14) Scenario 2 (leftward movement from a non-left-edge position) *[ $\left[\mathrm{D}^{\prime} \ldots \ldots \underset{\wedge}{\mathrm{Y}} \alpha\left[\begin{array}{llll}\mathrm{D} & \mathrm{X} & t_{\mathrm{Y}} \mathrm{Z}\end{array}\right]\right]$

$$
\begin{array}{lll}
\text { Ordering: } & \begin{array}{l}
\mathrm{Y}<\boldsymbol{\alpha} \\
\boldsymbol{\alpha}<\mathbf{D} \rightarrow \boldsymbol{\alpha}<\mathbf{X}
\end{array} & \mathrm{X}<\mathrm{Y}<\mathrm{Z}
\end{array}
$$


In (14), $\mathrm{Y}$ was not at the left edge of D. Consequently, the ordering statements added when $\mathrm{D}^{\prime}$ undergoes Spell-out are not consistent with the ordering statements previously added when D underwent Spell-out.

Let us see this in detail. The statement " $\alpha<D$ " is interpreted as " $\alpha$ precedes X" (see (11)). The ordering statements of the previous Spell-out domain included " $\mathrm{X}<\mathrm{Y}$ ". The ordering statements of the new Spell-out domain indicate that $\mathrm{Y}$ in turn must precede $\alpha$. This yields a contradiction when translated in the obvious manner into instructions for pronunciation: $\alpha$ must precede $\mathrm{X}, \mathrm{X}$ must precede $\mathrm{Y}$, but $\mathrm{Y}$ must precede $\alpha$. There is no way out of this loop, since the property of Order Preservation makes it impossible to disregard (e.g. delete) any of the ordering statements produced by Spell-out.

The consequence of this system should be clear. All things being equal, leftward movement from a Spell-out domain D must take place from the left edge of $\mathrm{D}$ (and conversely for rightward movement). This, as we have seen, is a property that can explain successive-cyclicity.

All things, however, are not always equal. In particular, we can now begin to discern some characteristics that distinguish our account of successive-cyclicity requirements from others. For one thing, our proposal accounts for "escape hatch phenomena" without invoking the concept of an escape hatch, as we shall illustrate below. This is a conceptual advantage that also has significant empirical consequences (but see note 9). Under particular circumstances, as we shall see, movement can extract an element from Spell-out domain D that did not occupy the relevant edge of D. Our proposal also differs from many others in tying successivecyclicity requirements to properties of the syntax-phonology interface. We thus might expect that certain variations in pronunciation might obviate the need for successive-cyclicity. We will suggest that the phenomenon of "salvation by deletion" directly reflects this property of our system. We turn to these matters in the next section.

\subsection{Novel predictions}

Consider again the abstract derivation sketched in (9) and extended in (12). The first new case to examine is one in which both $\mathrm{X}$ and $\mathrm{Y}$ in (12) move out of $D$ to positions to the left of $\alpha$. In standard approaches, 
movement of this sort should be impossible in principle, except under particular circumstances (e.g. multiple specifier constructions) in which both $\mathrm{X}$ and $\mathrm{Y}$ occupy "escape hatch" positions. In the system developed here, by contrast, such movement should be possible quite generally - so long as $\mathrm{X}$ and $\mathrm{Y}$ preserve their original order. This consequence of our system can be seen in Scenario 3 sketched in (15) below. Since X and Y preserve their original order, the new ordering statements added by Spell-out of $\mathrm{D}^{\prime}$ are consistent with the ordering statements already established in D.

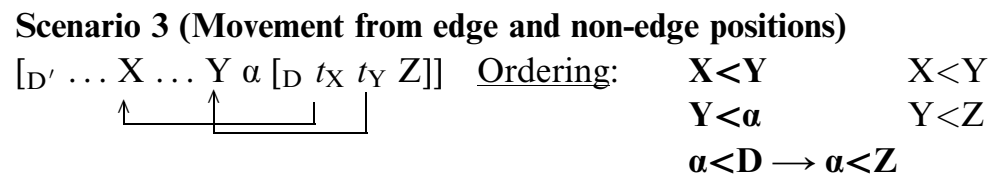

Under this scenario no ordering contradiction arises, despite the fact that $\mathrm{Y}$ is not moving from the left edge of D. In Scenario 2, in which Y moved alone, an ordering contradiction arose from the distinct orderings of $\mathrm{X}$ and $\mathrm{Y}$ before and after movement. Scenario 3 contrasts with Scenario 2 precisely because the relative ordering of $\mathrm{X}$ and $\mathrm{Y}$ remains the same before and after movement. We will see shortly that this contrast between the two scenarios is empirically confirmed by a number of phenomena.

A different variation on Scenario 2, which we mention only in passing here, yields another novel prediction. Suppose D in (14) undergoes ellipsis, as shown in (16), with the consequence that $\mathrm{X}$ (and Z) in D are not pronounced at all. On such a scenario, any ordering statement that makes reference to $\mathrm{X}$ (or $\mathrm{Z}$ ) has no impact on pronunciation. For ease of exposition, we can assume that these ordering statements are generated, but are deleted as a by-product of ellipsis. We indicate such deleted ordering statements with shading.

(16) Scenario 4 (leftward movement from a non-left-edge position + ellipsis)

$$
\begin{array}{cccc}
{\left[\mathrm{D}^{\prime} \ldots \stackrel{\mathrm{Y} \alpha\left[\mathrm{D} \mathrm{X} t_{\mathrm{Y}} \mathrm{Z}\right]}{\text { ellipsis }}\right.} & \text { Ordering: } & \mathbf{Y}<\boldsymbol{\alpha} & X<Y \\
\mathbf{\alpha}<\boldsymbol{D} \rightarrow \boldsymbol{\alpha}<\boldsymbol{X} & Y<Z
\end{array}
$$

As result of deleting the shaded statements in (16), movement of Y produces no ordering contradiction. We thus expect that ellipsis of a domain such as D will allow certain otherwise illicit instances of movement. In 
Fox and Pesetsky (in prep.), we argue that this prediction is true, and explains the phenomena often grouped under the rubric of "Salvation by Deletion" (Ross (1969); Chomsky (1972); Lasnik (2001); Merchant (to appear); Fox and Lasnik (2003)). ${ }^{8}$

We are now in a position to contrast our proposal with others, including other attempts to relate island phenomena to the syntax-phonology interface. As we have just seen, our proposal has the following consequences for a structure such as (12), repeated below as (17):

$$
\alpha[\mathrm{D} \text { X Y Z] }
$$

1. X may freely move leftward out of $\mathrm{D}$.

2. Y may move leftward out of D so long as it does not phonologically cross $\mathrm{X}$. Y moves out of D without phonologically crossing $\mathrm{X}$ if:

a. $\mathrm{X}$ has itself moved further to the left (Scenario 3), or

b. $\mathrm{X}$ is unpronounced as a consequence of ellipsis (Scenario 4).

Consequence 1 is what our proposal shares with theories that designate $\mathrm{X}$ as a specific escape hatch from $\mathrm{D}$. Consequence 2 is unique to our proposal. Though our proposal, like others, designates certain categories (the Spell-out domains) as special in a way that interacts with island phenomena, these categories are in no sense syntactically opaque.

Earlier accounts such as the Subjacency Condition stipulate the syntactic opacity of particular domains, and therefore are compelled to designate specific peripheral positions as exceptions to this opacity. Certain more recent proposals (e.g. Chomsky (2000, 2001a); Uriagereka (1999); Nissenbaum (2000)) share with our proposal a logical connection between island phenomena and the timing of Spell-out. These proposals differ from their predecessors in not stipulating the opacity of various domains - deriving it instead as a by-product of Spell-out. They do not differ from their predecessors, however, in the factual assumption of syntactic opacity, with the necessary consequence that designated syntactic escape hatches need to be postulated. The proposals of Chomsky and Nissenbaum express this conclusion by distinguishing the categories whose construction triggers Spell-out (phases) from the smaller categories

8 This argument is extended by Takahashi (2004) to Object Shift, thus drawing a connection between the two scenarios. Takahashi's work explores the syntax of pseudo-gapping and its consequences for linearizaton. 
that are actually spelled out (the Spell-out domains). Thus, for example, when the CP phase is constructed, it is a subconstituent of CP that is actually spelled out (IP or $v \mathrm{P}$ in different versions of this proposal). The spelled out domain - not the entire phase - thus becomes syntactically opaque. The phase minus its Spell-out domain constitutes the escape hatch. If Consequence 2 is correct, it is wrong to identify certain constituents as syntactically opaque, and there is no need to distinguish phases from Spell-out domains. ${ }^{9}$

The sections that follow constitute an extended argument that Consequence 2 is empirically correct. If these arguments are successful, we can conclude that the correct theory of "escape hatch effects" does not invoke the notion "escape hatch" in any form; and that the correct theory of "syntactic opacity effects" does not invoke the notion of a syntactically opaque domain. ${ }^{10}$

\section{Holmberg's Generalization}

Let us begin by considering how the abstract discussion above applies to the specific case of movement out of VP in a head-initial language. (We continue to ignore the base position of the external argument, consistent with the assumption that VP, rather than $v \mathrm{P}$, is the relevant Spell-out

9 Chomsky (2001a) has offered a conceptual argument in favor of a distinction between phases and Spell-out domains. In particular, he suggests that in an optimal architecture for language, domains previously constructed are inaccessible to later operations. As a consequence, later operations need not look into these earlier domains - thus (in many cases) shortening computations. At the same time, since operations do appear to cross domain boundaries, there must be an "edge zone" that belongs to the earlier domain but is accessible to operations in the higher domain. Our proposals are simpler in that they do not need to stipulate an "edge zone", though they might be viewed as weaker in allowing the syntax access to greater expanses of structure. The conceptual motivation for phases/Spell-out domains nonetheless remains similar to Chomsky's. Though we do permit the syntax to examine the contents of earlier domains, our proposals share with Chomsky's conception a certain "encapsulation" of these domains. The system never recomputes the linearization of earlier domains and thus allows communication with the phonological component, at least, to have a strictly local character. See section 7, as well as Fox and Pesetsky (in prep.) for further discussion.

10 It is interesting to note a prediction of our proposals not shared by most other theories: string-vacuous movement should not require successive-cyclicity, and should thus be immune to certain islands. Work by Sabbagh (2003) provides strong support for this conclusion from a detailed study of Right Node Raising and related constructions. 
domain; see footnote 2.) We are thus considering the situation in (9), with $\mathrm{X}=\mathrm{V}$ and $\mathrm{D}=\mathrm{VP}$, as shown in (18a). This VP undergoes Spell-out, establishing the ordering statements shown. In the next Spell-out domain, various elements may merge with the structure in (18). Consider the case in which an adverb merges with VP, as shown in (18b):

(18) Adv + VP

a. Spell-out of $V P$

[vP V Y Z]

Ordering: $\quad \mathbf{V}<\mathbf{Y}$

$\mathrm{Y}<\mathrm{Z}$

b. Adverb merges with $V P$

Adv [vp V Y Z]

Suppose Y now needs to move leftward to a VP-external position. As we have seen, this would be unproblematic if $Y$ had moved to the left edge of VP before Spell-out of VP, as we assume can happen in A-bar constructions. In the derivation sketched in (18), however, movement of $\mathrm{Y}$ into the higher Spell-out domain should be impossible unless the verb itself also moves leftward, landing in a position that preserves $\mathrm{V}<\mathrm{Y}$ order. This, we suggest, is the account of various constraints on Object Shift in Scandinavian languages that have been grouped under the rubric of "Holmberg's Generalization" (Holmberg (1986, 1998)).

As is known, Scandinavian languages such as Swedish show the phenomenon of verb-second, which we will assume involves movement to $\mathrm{C}$. The main verb of the sentence does not move to $\mathrm{C}$ in sentences that contain an auxiliary verb. In addition, embedded clauses in the mainland Scandinavian languages do not generally show verb-second.

When the main verb (V) moves to C, a DP object with certain semantic (or morphological) properties may (sometimes must) move leftward out of VP. The landing site of this movement is to the left of adverbs that can be shown to precede VP. Crucially, when V does not move to $\mathrm{C}$, Object Shift is impossible. This restriction is the most discussed case of Holmberg's Generalization, exemplified by the Swedish examples in (19): ${ }^{11}$

11 The examples in this section are taken from Holmberg (1998). 
(19) Object Shift blocked by (unmoved) verb intervener ${ }^{12}$

a. Jag kysste henne inte [vp $t_{v} t_{o}$ ]

I kissed her not

b. *... att jag henne inte [vp kysste $t_{o}$ ].

... that I her not kissed

c. *Jag har henne inte [vp kysst $t_{o}$ ].

I have her not kissed

These facts follow from Order Preservation under one key assumption: that Object Shift, unlike certain other instances of movement, does not proceed successive-cyclically through Spec,VP. When an object is preceded within VP by other material, Object Shift should instantiate the unacceptable scenario 2. If material that precedes the object also moves out of VP, it should instantiate the acceptable scenario 3, which (as noted above) is a novel prediction of our account of successive-cyclicity. Let us examine the facts.

Consider first the case in which Object Shift is accompanied by V-to-C movement, as in (19a). The sketch in (20) below shows that when the verb raises, the ordering of elements in the VP Spell-out domain is not contradicted by ordering established in the $\mathrm{CP}$ domain:

\section{Object Shift + V-movement to C}

a. VP: [VP $\mathrm{V}$ O]

Ordering: $\quad \mathbf{V}<\mathbf{O}$

b. CP: [CP $\mathrm{S} V$ [TP $\mathrm{t}_{\mathrm{S}} \mathrm{O}$ adv [vP $\left.\left.\mathrm{t}_{\mathrm{V}} \mathrm{t}_{\mathrm{O}}\right]\right]$

$\begin{array}{lll}\text { Ordering: } & \mathbf{S}<\mathbf{V} \quad \mathrm{V}<\mathrm{O} \\ & \mathbf{V}<\mathbf{O} \\ & \mathbf{O}<\mathbf{a d v} \\ & \mathbf{a d v}<\mathbf{V P} \rightarrow \boldsymbol{0}\end{array}$

12 When Object Shift of a pronoun is possible, it is obligatory. When Object Shift is blocked, as in $(19 b-c)$, the pronoun appears in its unshifted position to the right of the verb and negation. Our system is in general compatible with a variety of approaches to this "obligatory movement up to Holmberg's Generalization", e.g. covert movement when overt movement is blocked (Bobaljik (2002)). Bobaljik's particular implementation of this proposal, which relies on a view of movement as copying, is not straightforwardly compatible with the view of movement that we adopt in section 7 . We leave this issue open. 
When VP is Spelled out, it is established that V precedes O. V continues to precede $\mathrm{O}$ in the $\mathrm{CP}$ spell-out domain. Since VP dominates only traces, the statement " $\mathrm{adv}<\mathrm{VP}$ " has no consequences for pronunciation (as indicated by " $\rightarrow \varnothing$ ") and creates no contradictions. ${ }^{13}$ (If VP contained non-null post-object material, the statement " $\mathrm{adv}<\mathrm{VP}$ " would, of course, order the adverb before this material.) This instantiates scenario 3 .

Consider now derivations in which Object Shift is not accompanied by V-to-C movement. As (19b-c) showed, the result is unacceptable. In (21), we illustrate how this is accounted for by Order Preservation in the case of (19b), where the presence of a complementizer blocks V-to-C movement.

\section{* Object Shift without V-movement to C (embedded clause)}
a. VP: [vP $\mathrm{V}$ O]
Ordering: $\quad \mathbf{V}<\mathbf{O}$

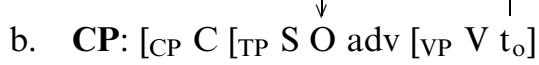
Ordering: $\quad \mathbf{C}<\mathbf{S} \quad \mathrm{V}<\mathrm{O}$
$\mathbf{S}<\mathbf{O}$
$\mathbf{O}<\mathbf{a d v}$
$\operatorname{adv}<\mathrm{VP} \rightarrow \operatorname{adv}<\mathrm{V}$

In (21), the ordering statements produced at Spell-out of $\mathrm{CP}$ do contradict the statement " $\mathrm{V}<\mathrm{O}$ " produced at Spell-out of VP. Given "O $<$ adv" and "adv $<\mathrm{V}$ ", $\mathrm{O}$ must precede $\mathrm{V}$, which contradicts " $\mathrm{V}<\mathrm{O}$ ", thus instantiating the unacceptable scenario 2 .

When Aux moves to $\mathrm{C}$ and $\mathrm{V}$ remains in situ, as in matrix clauses like (19c), Object Shift yields the same contradiction, as we can see in (22):

(22) *Object Shift without V-movement to $\mathbf{C}$ (matrix clause with auxiliary verb)

a. VP: [VP $\mathrm{V} \mathrm{O}]$

Ordering: $\quad \mathbf{V}<\mathbf{O}$

13 We show the subject moving to Spec,CP, as in analyses of Verb-second that follow the original proposal of den Besten (1983). There are alternative proposals, stemming from Travis (1984) and Zwart (1996), according to which the verb in an SVO sentence moves only as far as T and the subject only as far as Spec,TP. This analysis would involve the same ordering as that shown in (20). 
b. CP: [CP $\mathrm{S}$ aux [TP $\mathrm{t}_{\mathrm{S}} \mathrm{O}$ adv $\left.\left.\mathrm{t}_{\mathrm{aux}}\left[\mathrm{vp}_{\mathrm{V}} \mathrm{Vt}_{\mathrm{o}}\right]\right]\right]$

$\begin{array}{lll}\text { Ordering: } & \mathbf{S}<\text { aux } & \mathrm{V}<\mathrm{O} \\ & \text { aux }<\mathbf{O} \\ & \mathbf{O}<\text { adv } \\ & \text { adv }<\text { VP } \rightarrow \text { adv }<\text { V }\end{array}$

Alternative proposals have been advanced that also account for the facts in (19). These proposals focus on syntactic or morphological consequences of verb movement per se. An example of a verb-centered syntactic alternative is the proposal of Chomsky (1993). This proposal assumed a clause structure in which Object Shift and the obligatory raising of the subject create locality problems that can only be resolved by movement of the verb (under the assumption that verb movement expands the domains of locality). A verb-centered morphological alternative was offered by Bobaljik (1994, 1995, 2002), who proposed that a verb must be adjacent to an inflectional head from which it receives its morphology. Object Shift disrupts this adjacency unless the verb raises over the object.

Verb-centered accounts of the facts in (19) have been called into serious question, however, by Holmberg (1998), who made the following observation: "Less often mentioned, but no less true, is the fact that not just an unmoved verb, but any phonologically visible category inside VP preceding the object position will block Object Shift." The examples in (23) substantiate this observation. Note that Object Shift is blocked in each of these examples despite the fact that $\mathrm{V}$ has moved to C. Object Shift in each case is blocked by a different intervener, marked with an underline:

(23) OS blocked by non-verb interveners ${ }^{14}$

a. First-object intervener

*Jag gav den inte [vp $t_{v}$ Elsa $t_{o}$.

I gave it not Elsa

b. Particle intervener

*Dom kastade mej inte [vp $\mathrm{t}_{\mathrm{v}} \underline{\text { ut }} \mathrm{t}_{\mathrm{o}}$ ].

They threw me not out

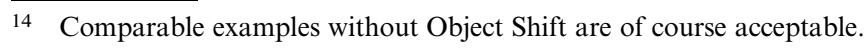


These facts do not follow from verb-centered accounts of (19). They suggest that the ability of an element to block Object Shift is not related to its categorial status. Verbs and other elements act alike. Instead, as stressed by Holmberg, it is the linear position of an element that is responsible for the intervention effect. (Holmberg develops this observation as part of an argument that a phonological version of "Relativized Minimality" applies to certain instances of movement. His proposal has some important points of contact with ours, to which we return below.) It should be clear that Holmberg's observations are an automatic consequence of our theory of linearization. They are simply another instantiation of "scenario 2". In each example in (23), Spellout of VP yields an ordering statement of the form "intervener $<$ " " which is contradicted by the ordering statements produced at Spell-out of $\mathrm{CP}$, once the object has moved leftward over the intervener. This is sketched in (24), where "XP" is the first object or particle intervener in (23):

OS blocked by non-verb interveners (scenario 2)

VP: [vP V XP O]

Ordering: $\quad \mathbf{V}<\mathbf{X P}$

$\mathrm{XP}<\mathrm{O}$

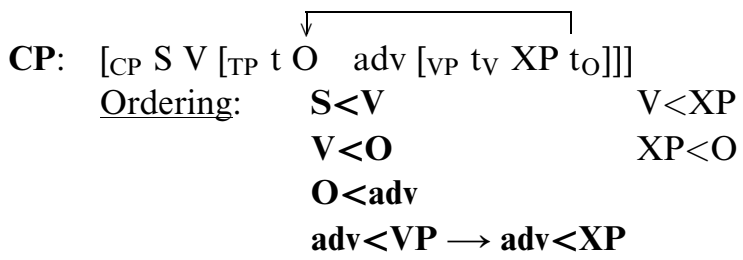

The ordering contradiction in (24) is readily apparent. On the one hand, it is established as part of Spell-out of VP that XP precedes O. When CP is spelled out, however, it is determined that $\mathrm{O}<\mathrm{Adv}$ and $\mathrm{adv}<\mathrm{XP}$, which contradicts what was established at the VP level.

Just as the effects observed by Holmberg in (23) instantiate scenario 2, we expect to find ways of obviating these effects that instantiate scenario 3. More specifically, our linearization-based account makes a further 
prediction. Ordering contradictions produced by Object Shift over the underlined interveners in (23) should be circumvented whenever the original order is restored - i.e. by movement into the higher Spell-out domain of not only the shifted object, but also the intervener. Holmberg's (1998) observations in (25) corroborate this prediction. When the interveners in (23) undergo movement to a position to the left of the landing site for Object Shift, the impediment to Object Shift is removed:

\section{(25) OS not blocked when non-verb intervener moves further to the left $^{15}$}

a. First object intervener moves

$\underline{\text { Vem }}_{\text {IO }} \operatorname{gav}_{\mathrm{V}} \mathrm{du} \mathrm{den}_{\mathrm{O}}$ inte [vP $\left.\mathrm{t}_{\mathrm{V}} \mathrm{t}_{\mathrm{IO}} \mathrm{t}_{\mathrm{O}}\right]$. who gave you it not

b. Particle intervener moves

$\underline{U T}_{P}$ kastade dom mejo inte [vP $\left.t_{V} t_{P} t_{O}\right]$

out threw they me not

(bara ned för trappan).

(only down the stairs)

In (26), we can see why no ordering contradiction arises. We assume that the XP intervener (unlike the shifted object) moves first to the left edge of VP (as discussed in section 2) before undergoing further A-bar movement to Spec,CP. This initial step also serves to place the intervener to the left of $\mathrm{V}$, an ordering preserved at the $\mathrm{CP}$ level:

15 A preposition in PP may also act as an intervener for Object Shift of its object, as noted by Holmberg:

$\left.\begin{array}{ccccc}\text { *Jag } & \text { talade } & \text { henne inte } & {\left[\mathrm{vP}_{\mathrm{v}}\right.} & \underline{\text { med }} \mathrm{t}_{\mathrm{o}}\end{array}\right]$

We do not have instances of P-topicalization or wh-movement comparable to the examples in (25) that allow us to see whether this effect too may be circumvented. 
(26) OS not blocked when non-verb intervener moves further to the left (scenario 3)

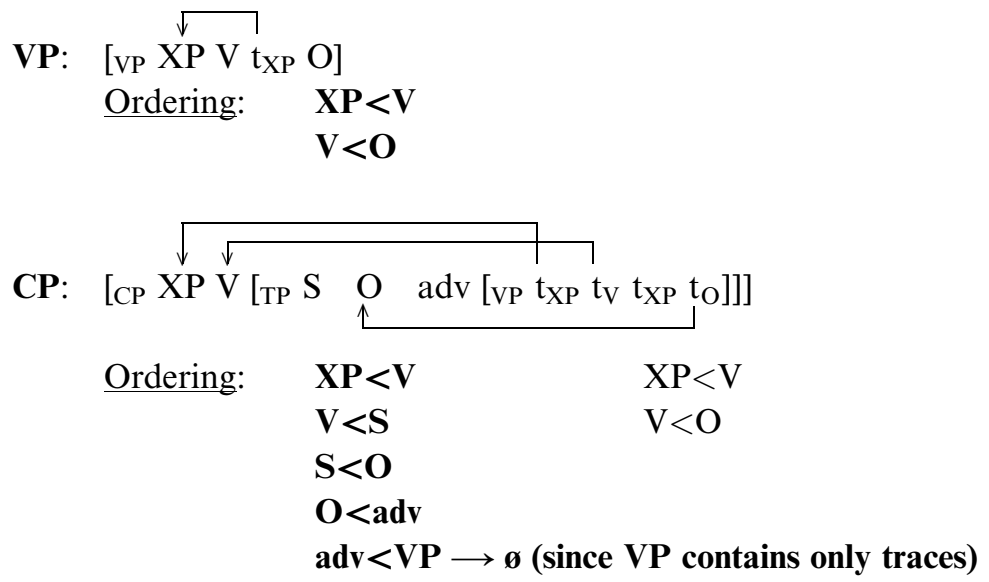

The relative ordering of XP, V and O, established at Spell-out of VP, is not contradicted by any statements added when CP is spelled out.

An additional observation by Holmberg (1998) is of particular interest. Holmberg pointed out that Object Shift is possible not only when V moves to $\mathrm{C}$ but also when $\mathrm{V}$ appears by itself in Spec, $\mathrm{CP}$ due to a process that we will call "Bare V topicalization", exemplified in (27).

\section{Bare V topicalization}

a. Kysst har jag henne inte (bara hållit henne i handen). kissed have I her not (only held her by the hand)

b. Sett $\underline{v}$ har han me kanske $t_{0} \ldots$ seen has he me perhaps (men han vet inte vad jag heter). (but he knows not what I am called)

It is immediately obvious that our proposal predicts the acceptability of Object Shift in these examples, even though $\mathrm{V}$ has not moved to $\mathrm{C}$. Thanks to the fronting of the bare $\mathrm{V}$, the object follows $\mathrm{V}$ when $\mathrm{CP}$ is spelled out (after Object Shift), just as it did when VP was spelled out. What is relevant to the acceptability of Object Shift is the relative ordering of $\mathrm{V}$ and $\mathrm{O}$ at the various points of Spell-out, not the nature of the syntactic processes that establish these orderings. 
Nonetheless, the proper syntactic analysis of Bare V Topicalization turns out to be of interest in the present context. As noted by Holmberg, one might analyze this construction in one of two ways. Bare V Topicalization might involve raising of $\mathrm{V}$ to $\mathrm{Spec}, \mathrm{CP}$ - an instance of head movement to a specifier position, raising issues for the Head Movement Constraint: ${ }^{16}$

(28) Bare V Topicalization analysis \#1: Object Shift + V-movement to Spec, CP

a. VP: [vp V O]

Ordering: $\quad \mathbf{V}<\mathbf{O}$

b. CP: [CP $\mathrm{V}$ aux [TP $\mathrm{S}$ O adv $\left.\left.\mathrm{t}_{\mathrm{aux}}\left[\mathrm{vp} \mathrm{t}_{\mathrm{V}} \mathrm{t}_{\mathrm{O}}\right]\right]\right]$

$\begin{array}{ll}\text { Ordering: } & \mathbf{V}<\text { aux } \quad \mathrm{V}<\mathrm{O} \\ & \text { aux }<\mathrm{S} \\ & \mathbf{S}<\mathbf{O} \\ & \mathbf{O}<\mathbf{\text { adv }} \\ & \text { adv }<\mathbf{V P} \rightarrow \boldsymbol{\text { o }}\end{array}$

Alternatively, one might analyze Bare V Topicalization as movement of a VP from which non-head constituents have been previously extracted - an instance of VP "remnant movement". If Bare V Topicalization is an instance of head raising, then the examples in (27) simply instantiate Scenario 3. If Bare V Topicalization is an instance of VP remnant movement, it instantiates an interesting variant of Scenario 3 in which $X$ ends up to the left of $\mathrm{Y}$ not because $\mathrm{X}$ itself moves, but because a category that contains $\mathrm{X}$ (and formerly contained $\mathrm{Y}$ ) moves. This possible derivation is sketched in (29):

16 It is possible that all head movement, including V-to-C movement, forms a specifier, with the moved head amalgamating with its host by a separate process. Such an analysis has been proposed by Matushansky (to appear) (see also Fukui and Takano (1998); Toyoshima (2001); Pesetsky and Torrego (2004)). This possibility does not eliminate the question raised in the text about the Head Movement Constraint. Note also that the topicalized verb in the Bare $\mathrm{V}$ Topicalization construction does not amalgamate with the auxiliary verb that occupies $\mathrm{C}$. 


\section{(29) Bare V Topicalization analysis \#2: Object Shift + remnant VP topicalization}

VP: [vp V O]

$$
\text { Ordering: } \quad \mathbf{V}<\mathbf{O}
$$

\section{Remnant VP Topicalization}

$\mathrm{CP}: \quad\left[\mathrm{CP}\left[\mathrm{vP} \mathrm{V} t_{\mathrm{O}}\right]\right.$ aux [TP $\mathrm{S} \mathrm{t}_{\mathrm{aux}}{ }_{\wedge}^{\mathrm{O}} \operatorname{adv} t_{[\mathrm{vP}} \mathrm{V}$ to] $\left.\left.]\right]\right]$

\section{Object Shift}

\begin{tabular}{|c|c|}
\hline Ordering: & $\begin{array}{l}\mathrm{VP}<\text { aux } \rightarrow \mathrm{V}<\text { aux } \\
\text { aux }<\mathrm{S} \\
\mathrm{S}<\mathrm{O} \\
\mathrm{O}<\mathrm{ady}\end{array}$ \\
\hline
\end{tabular}

As indicated above, when VP is spelled out, it is established that V precedes O. In the process of building CP, Object Shift applies, followed by topicalization of the VP that the object was extracted from. (The auxiliary verb also raises to $C$, in keeping with the verb-second character of the language.) When $\mathrm{CP}$ is spelled out, new ordering statements are added, including "VP $<$ aux". Crucially, the last element of VP (not dominated by a trace) is now the verb itself, so by (11), the statement "VP<aux" means that V precedes the auxiliary verb. Since the V precedes the auxiliary verb, and the auxiliary verb precedes the object, the resulting ordering is fully consistent with the statement " $\mathrm{V}<\mathrm{O}$ " established in the earlier spell-out domain.

A combination of Object Shift and VP-remnant movement must in fact be possible. When VP contains material besides the verb and a direct object, this material may front along with the verb even when the direct object is first extracted by Object Shift. Crucially, since material that is fronted along with the verb ends up preceding the shifted object, it must already have preceded the object when the VP was spelled out. Thus, for example, the fact (seen in (23a)) that the indirect object is ordered before the direct object within VP means that this ordering must be preserved if both Object Shift and VP-remnant movement apply. ${ }^{17}$ As a consequence,

17 This prediction of our proposal was brought to our attention by Alec Marantz (personal communication). Anders Holmberg offered the facts in (30a-b) as confirmation of this prediction. 
the indirect object may be topicalized with the verb to the exclusion of the direct object, but the direct object may not be topicalized with the verb to the exclusion of the indirect object. This contrast may be seen in $(30 a-b)$ :

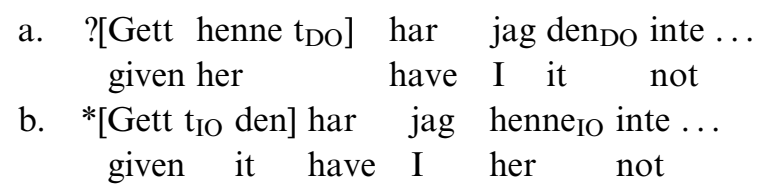

Likewise, Object Shift applied to the subject of an ECM complement followed by remnant movement of the higher VP should be impossible, since the remainder of the ECM complement followed the subject when the higher VP was spelled out. This prediction is correct, as can be seen in the following example from Holmberg (1998): ${ }^{18}$

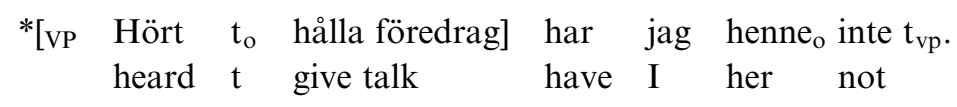

It is instructive at this point to consider the conclusions that Holmberg himself drew from the ill-formedness of (31). A consideration of Holmberg's analysis of such examples brings out another way in which our proposal differs from certain predecessors. Holmberg's analysis anticipated ours in attributing significant constraints on Object Shift to phonological factors related to linear precedence. It was Holmberg who first argued that Object Shift may not apply so as to alter linear precedence relations. Crucially, however, Holmberg proposed that this constraint is a condition on the application of Object Shift itself: Object Shift may not cross a phonological intervener. The fact that leftward movement of an intervener may save a derivation in which Object Shift applies both supported Holmberg's proposal and posed a problem for it at the same time. In (25), for example, movement to Spec, $\mathrm{CP}$ of an indirect object or particle permits an otherwise blocked instance of Object Shift. This type of fact was taken as a demonstration that phonologically null interveners (e.g. traces) do not block Object Shift, thus arguing for the phonological character of the phenomenon. On the other hand, since the phonological

18 See Nilsen (2003) for additional arguments for VP remnant movement in Norwegian, in the context of a proposal substantially different from ours. 
constraint that governs Object Shift was viewed as a constraint on the operation itself, Holmberg had to conclude that Object Shift in such cases applies after the rules that move the intervener, and thus must apply countercyclically. Holmberg suggested that Object Shift applies in a post-syntactic PF component, thus simultaneously making sense of its apparent countercyclic character and its sensitivity to linear precedence.

What is particularly interesting about Holmberg's proposal in the present context is its incompatibility with a remnant movement analysis of Bare V Topicalization. When movement of the object via Object Shift interacts with movement of an independent constituent, it is possible to posit an ordering of the two operations such that Object Shift applies after the independent intervener has moved. Thus, in (25), Object Shift can be viewed as applying after movement of an indirect object or particle to Spec,CP. Likewise, if Bare V Topicalization is analyzed as in (28), Object Shift can be viewed as applying after V-movement. By contrast, if what looks like $\mathrm{V}$-movement in the Bare $\mathrm{V}$ Topicalization construction is actually movement of a remnant VP from which the object has been extracted, it must obviously be the case that Object Shift precedes the movement that allows it to escape the phonological intervention constraint and thus it cannot be claimed that the phonological condition on Object Shift is a condition on the rule itself, as assumed by Holmberg.

Our proposal is similar to Holmberg's in the phonological nature of its explanation for constraints on Object Shift. Our proposal differs from Holmberg's in regarding the phonological constraint on Object Shift not as a constraint on the operation of the rule itself, but as a domain-final constraint on output. ${ }^{19}$ It is quite expected under our proposal that Object Shift may cross elements which, if they did not later move, would create an ordering contradiction - so long as these elements do move before the next application of Spell-out. Thus, the remnant movement analysis of Bare V Topicalization is available to us, and to the extent that it can be supported, would provide further evidence for our proposal.

19 In this sense, our version of Holmberg's phonological constraint operates as a filter, rather than as a condition on a rule (thus resembling the models of predecessors mentioned in footnote 5). Note, however, that it is not a stipulated filter. Instead, it is simply the process of linearization in a model within which linearization statements, once made, cannot be unmade. 
We have already seen in (30) some evidence that remnant VP topicalization does exist and interacts with Object Shift as predicted by our proposal. Holmberg himself notes potential further evidence provided by ECM constructions like those in (32). If it were possible to raise $\mathrm{V}$ to Spec,CP, we would incorrectly expect $(32 \mathrm{a}-\mathrm{b})$ to be acceptable with the analysis indicated:

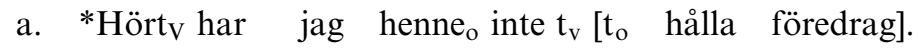
heard have I her not give talk

b. *Hört ${ }_{v}$ har jag inte $t_{v}$ [Per hålla föredrag]. heard have I not Peter give talk

If $\mathrm{V}$ movement to Spec, $\mathrm{CP}$ is impossible, the analyses shown in (32) are of course unavailable. The word order in $(32 \mathrm{a}-\mathrm{b})$ would have to be derived by extracting the ECM infinitival from VP to a position to the right of inte (in addition to applying Object Shift in (32a)) before fronting the remnant VP. Given the general, independently observable impossibility of fronting ECM infinitivals in languages such as Swedish, this initial step can be excluded, as Holmberg himself points out - thus explaining the ungrammaticality of the examples. ${ }^{20}$ Under a V-movement analysis, there does not appear to be a simple alternative, though Holmberg (1998) does sketch a tentative proposal related to the assignment of case.

If $\mathrm{V}$-movement to Spec, $\mathrm{CP}$ does not exist and all Bare V Topicalization is remnant VP movement, we must analyze examples like those in (33) from Holmberg (1998) as involving (short) extraction of PP or DP followed by VP remnant topicalization. The relevant short extraction cannot be Object Shift (as Holmberg notes) since Object Shift is largely limited to pronouns.

(33) a. Sag gjorde han på henne (but he said nothing). looked did he at her

20 In English, Heavy Shift may perhaps be followed by remnant VP topicalization, e.g. Read we did the books that she recommended. Heavy Shift of an ECM infinitive seems unacceptable, especially with remnant VP topicalization:

(i) ??Mary saw with her binoculars Bill give that talk we were expecting.

(ii) *See she did Bill give that talk.

The VP of an ECM infinitive also may not be stranded:

(iii) *See Bill she did give that talk. 
b. Sett har jag inte den idioten. seen have I not the idiot (but I have talked with him on the telephone)

In all examples of this sort, our proposal makes a key prediction that is (as far as we can tell) confirmed by the available data. Whatever material fails to front under remnant VP topicalization in examples like (33) must be drawn from the right periphery of the fronted VP, so that the original order is retained. ${ }^{21}$

We have just seen some reasons to view Holmberg's Generalization as a consequence of an Order Preservation property of domain-final syntaxphonology mapping rather than as a constraint on particular movement operations. $^{22}$ Once one views Holmberg's Generalization as a con-

21 Note also that if Bare V Topicalization is remnant VP fronting, as we have argued, then what needs to be preserved from phase to phase is clearly linear order, not some other relation, e.g. c-command. The preservation of V-O order after remnant VP movement, for example, satisfies the requirements of our system, even though the combination of Object Shift and remnant VP fronting produces a c-command configuration quite different from that which preceded these movement processes. See Williams (2003), 17-21 and Müller (2000) for some relevant discussion.

22 Other alternatives need to be carefully considered as well. Bobaljik (2002) and Anagnostopoulou (2003) have argued that the various blocking effects for Object Shift should not receive a uniform explanation. The blocking effect of an unmoved verb is attributed by Anagnostopoulou to Relativized Minimality interactions involving the external argument, along the lines of Chomsky (1993) - with verb movement to T creating an "equidistance" exception. The same phenomenon is attributed by Bobaljik to a morpho-phonological adjacency condition on $\mathrm{V}$ and a higher functional head, disrupted by Object Shift when $\mathrm{V}$ fails to raise.

The blocking effect of an indirect object on Object Shift of the direct object is attributed by both Anagnostopoulou and Bobaljik to Relativized Minimality interactions between the two objects. Anagnostopoulou suggests that the ameliorating effect of A-bar movement of the indirect object might follow from special properties of traces, as in (Chomsky (2000); Chomsky (2001a)).

The blocking effect of a particle in Swedish is related (by Bobaljik) to the general incompatibility of independently occurring particles in the Swedish passive (Svenonius 1996). Svenonius notes, however, that incorporation of the particle into the passive participle permits the passive, which suggests to us that the incompatibility of Swedish passive with particles is an independent phenomenon, related to the morphological interactions between particle incorporation and finiteness found elsewhere in Germanic not a fact to be considered in parallel with the blocking effect of particles on OS with finite verbs. 
sequence of domain-final syntax-phonology interaction, one expects the precise size of the relevant domains to have empirical consequences. Consider, for example, the fact that our proposal in effect distinguishes two types of movement that interact with the phonology in distinct ways. When a pair of elements have been ordered in a previous Spell-out domain, movement in a later Spell-out domain may not apply so as to reorder these elements; but a pair of elements that have not yet been ordered may undergo whatever movement the laws of syntax require, without fear of producing an ordering contradiction. It is the identity of the Spell-out domains that determines which movements belong to which category. This property of our proposal is directly reflected in the data discussed in this section. Because the lower Spell-out domain in Swedish contains $\mathrm{V}$ and the direct object $\mathrm{O}$, but does not contain adverbs or negation, Object Shift is free to move across adverbs without any danger of an ordering contradiction, but is not free to move across V. In a system such as Holmberg's, where the relevant condition is not domain-limited, this difference between VP-external elements (such as adverbs) and VPinternal elements (such as $\mathrm{V}$ and $\mathrm{O}$ ) is not expected.

\section{An Inverse Holmberg Effect}

We began our discussion with the observation that apparent longdistance leftward movement (e.g. wh-movement or topicalization) conforms to Order Preservation only if it proceeds via the left edge of each Spell-out domain that it crosses. In this way, we explained its successivecyclic character. We then noted a further prediction of Order Preservation:

The obviation of the verb blocking effect by V-topicalization is not explained by Bobaljik or by Anagnostopoulou.

We suspect that the uniformity of our proposal across these various constructions (a property inherited from Holmberg 1999) argues in its favor, though there might be possible elaborations of the alternative views that would pose challenges. Anagnostopoulou documents a wide variety of cases in which constraints on A-movement are obviated by other movement operations, some of them not obviously order-preserving. We leave a fuller comparison for future work. For some comparative comments in a different context, see Ko (2004). 
that even an element that does not occupy the left edge of a Spell-out domain may be moved leftward from that domain so long as elements to its left also move in a fashion that preserves the original linear order. Our example of this scenario was Object Shift, where an object preceded by V within VP could be extracted from VP so long as V also moved to a position preceding the landing site of the object.

Our proposal makes further important predictions (for VO languages) about constructions that combine movement of an element to the left edge of VP (as in $w h$-movement or topicalization) with verb movement. Consider the ordering consequences of movement of a postverbal element such as a direct object to the left edge of VP. Such movement will establish $\mathrm{O}<\mathrm{V}$ order when $\mathrm{VP}$ is spelled out. If $\mathrm{V}$ later raises to $\mathrm{C}$, and $\mathrm{O}$ moves to Spec, $\mathrm{CP}$, as in $w h$-movement, $\mathrm{O}<\mathrm{V}$ order is preserved, as seen in (34) and (35):

(34) Ven kysste jag?

who kissed I

'Who did I kiss?'

(35) Successive-cyclic $\boldsymbol{w h}$-movement $+\mathrm{V}$-movement to $\mathrm{C}$

a. VP: $\quad\left[\begin{array}{lll}\sqrt{\mathrm{O}} \mathrm{O} & \mathrm{t}_{\mathrm{o}}\end{array}\right]$

Ordering: $\quad \mathbf{O}<\mathbf{V}$

b. CP: [CP $\left.\begin{array}{llllll}\stackrel{\sqrt{O}}{\mathrm{O}} & \mathrm{V} & \mathrm{S}[\mathrm{vP} & \mathrm{t}_{\mathrm{o}} & \mathrm{t}_{\mathrm{v}} & \mathrm{t}_{\mathrm{o}}\end{array}\right]$

$\begin{array}{lll}\text { Ordering: } & \mathbf{S}<\mathbf{V P} \rightarrow \boldsymbol{0} & \mathrm{O}<\mathrm{V} \\ & \mathbf{V}<\mathbf{S} \\ & \mathbf{O}<\mathbf{V}\end{array}$

The second step of object movement is crucial in (35). If, instead of moving to Spec,CP, the object had either remained at the left edge of VP or moved to a position lower than C, V-to-C movement would yield an ordering contradiction. Movement of this sort would thus display an "Inverse Holmberg Effect" - a local movement of a VP-internal element that is permitted only when V-raising does not take place. In fact, this effect appears to be attested.

Several Scandinavian languages, including Icelandic, show a phenomenon known as "Quantifier Movement" (QM) (Rögnvaldsson 
(1987); Jónsson (1996); Svenonius (2000)). ${ }^{23}$ A quantified expression that undergoes QM moves leftward across VP-internal material, landing in a VP-external position slightly lower than the landing site of Object Shift. QM thus fails to obey Holmberg's Generalization, as can be seen in the Icelandic QM sentences in (36).

(36) Quantifier Movement (Icelandic) ${ }^{24}$

a. Jón hefur ekkert [sagt Sveini__].

Jon has nothing said Svein-DAT

'Jon has told Svein nothing.'

b. Äg hef mörgum bókum skilað Jóni.

I have many books returned Jon-DAT

'I have returned many books to Jon.'

c. Hann mun mikið hafa vilja [lesa _].

he will much have wanted read

'He has wanted to read much.'

If our proposals are correct, the quantified expression in these examples must have stopped at the left edge of VP before landing in its final position - a VP-external position, as shown clearly in (36c). This intermediate landing site is necessary because in (36) the phrase moved by QM precedes VP-internal material. This is material that it would have ended up following if QM had not applied. If QM first targets the left edge of VP, the order found in $(36 \mathrm{a}-\mathrm{c})$ is already established when VP is spelled out, and no contradiction arises. ${ }^{25}$

23 QM in Norwegian behaves differently from its counterparts in the other Scandinavian languages, and actually appears to obey Holmberg's Generalization. Our remarks about QM should be understood as excluding Norwegian, where QM presumably does not proceed via the left edge of VP as it does in the other languages under discussion (Christensen (1986, 1995); Svenonius (2000)).

24 We gloss over another factor relevant to the proper analysis of QM. Negative quantified expressions in Scandinavian appear to undergo QM obligatorily, at least where QM makes a difference to word order (Jónsson (1996, 94); Christensen (1995); Svenonius (2000)).

25 It is crucial either that the subject is outside the domain spelled out when VP is linearized or else that the quantified expression "tucks in" below the subject in Spec, $v \mathrm{P}$. The fact that V-to-C movement may place the verb to the left of the subject in certain verbsecond constructions suggests the former conclusion. For further discussion of the status of subjects with respect to the VP Spell-out domain, see Fox and Pesetsky (in progress) and Ko (2004). 
If QM involves an intermediate landing site at the left edge of VP, we predict an interesting interaction between $\mathrm{QM}$ and V-movement. Linearization of VP orders the moved quantifier not only to the left of elements such as the indirect object, but also to the left of $\mathrm{V}$ itself. As a consequence, V-to-C movement should be blocked when QM occurs: ${ }^{26}$

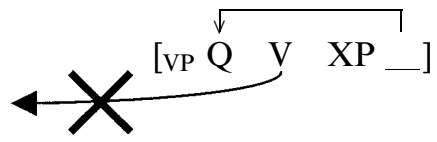

This expectation is borne out and represents exactly the situation just discussed under the rubric of an "Inverse Holmberg Effect". Example (38) is a minimal variation on (36a), differing only in the absence of an auxiliary verb, which forces main verb movement to $C$. As indicated, once this minimal variation is introduced, QM is no longer possible: ${ }^{27}$

\author{
QM to left edge of VP incompatible with V-to-C movement \\ *Jón sagði ekkert Sveini \\ Jon said nothing Svein-DAT \\ (Rögnvaldsson (1987), quoted by Svenonius (2000))
}

26 It is not crucial to assume that $\mathrm{V}$ in Icelandic subject-first main clauses actually moves to C. What is important is simply the fact that $\mathrm{V}$ moves to a position higher (and to the left of) the landing site of QM - the same position in (38) as that occupied by the (highest) auxiliary verb in (36). This position might be lower than $\mathrm{C}$, in light of the possibility of embedded verb-second constructions in Icelandic (and in light of Travis (1984) and Zwart (1996)'s more general proposal that V in Germanic SVO constructions occupies T, rather than C). See Iatridou and Kroch (1992), among others, for more discussion.

27 One might argue that examples like (38a) are actually excluded because the indirect object (Sveini) must undergo Object Shift when Object Shift is not independently impossible. Given that the Object Shift position appears to be slightly higher than the QM position, obligatory Object Shift would also enforce $\mathrm{IO}<\mathrm{DO}$ order. This view would be consistent with the acceptability of (36), given that OS is in fact impossible in such sentences (Holmberg's Generalization). In fact, however, though some speakers have a preference for OS of full DPs when OS is possible, this judgment appears to represent nothing more than a preference. Jónsson (1996), for example, notes the acceptability of such examples as (i), in which the position of the adverb makes it clear that OS has not applied to the full DP Mariu:

Jón sagði hreinlega Maríu alla söguna.

John told simply Mary whole story-the

'John simply told Mary the whole story.' 
The ordering contradiction produced by the combination of $\mathrm{QM}$ and V-to-C movement in (38) is shown schematically in (39):

\section{$* \mathbf{Q M}+\mathbf{V}$-movement to $\mathbf{C}$}

a. VP: $\quad\left[\mathrm{vP} \mathrm{O} \mathrm{V} \mathrm{IO}_{\mathrm{o}}\right.$ ]

Ordering: $\quad \mathbf{O}<\mathbf{V}$

$\mathrm{V}<\mathrm{IO}$

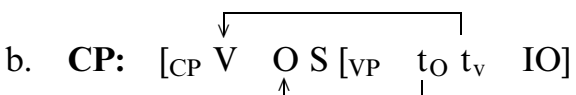

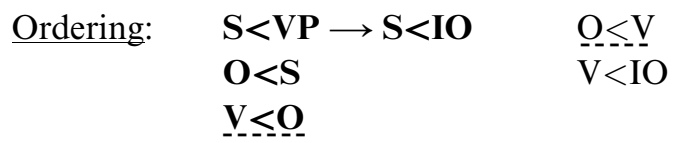

The impossibility of V-movement when $\mathrm{QM}$ applies, seen in the contrast between (36) and (38), is a general phenomenon, not limited to double-object constructions (as noted by Svenonius (2000)). In $(40 \mathrm{a}-\mathrm{b})$, in which $\mathrm{V}$ remains in situ, QM is seen crossing $\mathrm{P}$ and a direct object, in addition to $\mathrm{V}$ (with a slightly awkward outcome, as noted). In (40c-d), in which $\mathrm{V}$ moves to $\mathrm{C}, \mathrm{QM}$ is seen to be impossible, as predicted.

(40) a. Ég hef sett eitur í mörg glös.

I have set poison in many glasses

'I have placed poison in many glasses'

b. ?Ég hef mörg glös sett eitur í.

I have many glasses set poison in

c. Ég setti eitur í mörg glös.

I set poison in many glasses

d. *Ég setti mörg glös eitur í.

I set many glasses poison in [examples from Svenonius (2000)]

Likewise, (41a) shows long-distance QM from a controlled infinitival CP into a higher clause, which is once again incompatible with movement of the higher verb skipadi, as seen in (41b). 
(41) a. ?Hann hefur engum skipaði henni að giftast. he has nobody ordered her C to-marry

'He hasn't ordered her to marry anybody'

b. *Hann skipaði henni engum [vp $t_{\mathrm{V}}$ [CP að giftast_] he ordered her nobody $\quad \mathrm{C}$ to-marry

The contrast in (41a-b) has an additional feature of interest. Johnson and Vikner (1994) argue that infinitival verbs in control clauses raise to $\mathrm{T}$ in Icelandic, as demonstrated by the relative position of infinitival lesa and negation in (42).
a. María lofaði
að lesa
ekki bókina.
Maria promised C to-read not book-the
b. María lofaði að ekki lesa bókina.
Maria promised C not to-read book-the
(Sigurðsson (1989))

If the verb in examples like (41a) has also moved to T, we may conclude that QM is not in general incompatible with V-raising. The fact that the moved quantifier engum ends up preceding the embedded verb means that it must have moved through the left edge of the lowest VP as an initial step of movement. Subsequent raising of the embedded verb giftast to T of the embedded clause would create an ordering contradiction - but for the fact that engum itself has moved leftward once again (to Spec of the embedded CP, a position to the left of complementizer $a$ d), restoring engum $<$ giftast order. QM is thus compatible with V-raising for the same reason wh-movement in (34) is compatible with V-raising: movement to Spec,CP restores the order established when VP was spelled out.

This observation brings out a general characteristic of our proposals. In this section, we have discussed interactions among specific instances of movement: V-movement, QM and wh-movement. If our proposals are correct, however, we should not be surprised to discover very similar interactions in many other syntactic contexts. This is because, for us, these interactions arise exclusively from the linearization consequences of movement within and across Spell-out domains. Thus, though the ordering statements sketched in (35) and (39) included specific labels such as "V" and "O", they could just as well have been given more abstractly. 
For example, the role of "V" could be played by any element $X$ that would have occupied the left edge of VP if some other element $Y$ had not moved to its left. Such movement of $Y$ in general takes away the privileged status of $X$ as an "edge" element - i.e. an element that can move leftward in the next Spell-out domain without fear of ordering contradiction. We predict that whenever a situation of this sort arises, movement of $Y$ should block movement of $X$ (as in (39)) - with the now-familiar exception that arises when further instances of movement restore the original order of $X$ and $Y$ (as was the case with $\mathrm{V}$-to-C and wh-movement in (35)).

Recent work by Ko $(2003,2004)$ allows us to demonstrate this point quite nicely. She shows that certain long-standing problems in the analysis of scrambling have a straightforward explanation as generalizations of the paradigms in (35) and (39). In scrambling languages such as Korean and Japanese, as studied by Kuroda (1983) and Miyagawa (1989), among others, a quantifier may be stranded by movement of the associated nominal expression, as seen in (43):

Object scrambling over subject. stranding quantifier

\begin{tabular}{|c|c|c|c|c|}
\hline$\stackrel{\downarrow}{\mathrm{O}}$ & $\mathrm{S}$ & $t_{\text {obj }}$ & $\mathrm{NQ}_{\mathrm{obj}}$ & V] \\
\hline $\begin{array}{l}\text { Maykcwu-lul } 1 \\
\text { Beer-Acc }\end{array}$ & $\begin{array}{l}\text { John-i } \\
\text { John-Nom }\end{array}$ & $\mathrm{t}_{1}$ & $\begin{array}{l}\text { sey-pyeng } \\
\text { three-Cl bottle }\end{array}$ & $\begin{array}{l}\text { masi-ess-ta } \\
\text { drink-Past-Dec }\end{array}$ \\
\hline
\end{tabular}

Kuroda and Miyagawa argue that before scrambling, the quantifier and associated nominal expression are structurally close (e.g. sisters ${ }^{28}$ ) - and that it is movement that separates them under certain circumstances.

Given that scrambling seems to be free (and multiple scrambling is independently possible), it is interesting that object scrambling over a subject may not be followed by subject scrambling over the object, where the

28 Miyagawa's condition is slightly looser in ways that we will not discuss here. See also Ko (2004) for some discussion of a Korean construction in which the closeness condition does not obtain: a floating quantifier construction in which the quantifier agrees in casemarking with its associated nominal. This construction displays none of the key properties discussed in this section, for reasons discussed by Ko. 
subject scrambling strands a quantifier. This much-discussed observation (Haig (1980); Kuroda (1983); Saito (1985), Miyagawa (1989); Fujita (1994)) is dubbed the "Subject Puzzle" by Ko:

(44) The Subject Puzzle
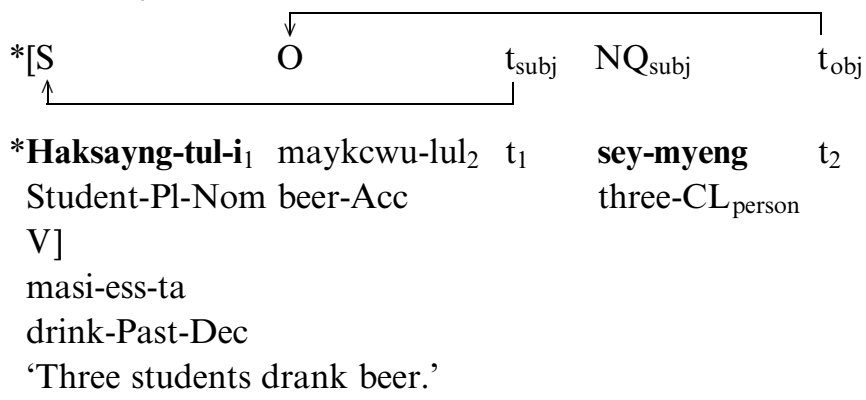

Saito accounted for the puzzle by proposing that subjects simply do not scramble. Ko, however, provides several arguments that Saito's proposal is incorrect. For example, long-distance scrambling of a subject is possible, as seen in (45): 29

(45) Long-distance scrambling of subject

John- $\mathrm{i}_{i} \quad$ [na-nun [ $\mathrm{t}_{i}$ Mary-lul ttayli-ess-ta-ko]]

John-Nom I-Top t Mary-Acc hit-Past-Dec-C

sayngkakha-n-ta

think-Pres-Dec

'John, I think that _ hit Mary.'

Likewise, scrambling of a subject over high adverbs such as way 'why' is possible, as seen in (46a). Subject scrambling in this construction may strand a quantifier, as seen in (46b):

(46) a. Subject scrambling over high adverb 'why' (way) ...

John- $\mathrm{i}_{i} \quad$ [CP way $\left[\mathrm{t}_{i}\right.$ Mary-lul ttayli-ess-ni]]?

John-Nom why $t$ Mary-Acc hit-Past-Q

'Why did John hit Mary?'

29 We present Korean examples only, but Japanese shows the same phenomena. 


\section{b. ... stranding a quantifier}

Hakpumo-tul-ika $a_{i}$ way $t_{i}$ sey-meyng hakkyo-lul

Parents-Pl-Nom why $t_{i} 3-C L \quad$ school-Acc pangmwunha-yess-ni? ${ }^{30}$

visit-Past-Q

'Why did three parents visit the school?'

Ko concludes that examples like (44) are not excluded by a general ban on subject scrambling. She argues instead that such examples are excluded by the linearization consequences of the various movements.

Central to Ko's analysis is an issue that we have sidestepped so far. If the subject originates within some type of VP, at what point in the derivation is it linearized with respect to other members of this phrase? ${ }^{31}$ Since the Scandinavian languages freely raise the main verb to $\mathrm{C}$ over the subject, the subject is presumably not linearized in Scandinavian with respect to the main verb before CP is constructed. That is one reason why we have referred so far to "VP" (rather than " $v \mathrm{P}$ ") as a Spell-out domain. If $v \mathrm{P}$ were a Spell-out domain in Scandinavian, verb-raising would yield an ordering contradiction. In Korean, however, Ko argues that $v \mathrm{P}$ is a Spell-out domain (possibly in addition to VP), and that the subject is therefore linearized with respect to VPinternal material before CP is built. We return to this apparent variation among languages in Fox and Pesetsky (in prep.), where we relate it to another source of variation (the overt/covert distinction). For now, we concentrate on the consequences of Ko's assumption for scrambling.

Ko's solution to the Subject Puzzle is based on the following observation. If $v \mathrm{P}$ is a Spell-out domain, an object that ends up preceding the external argument must first have scrambled to the edge of $\nu \mathrm{P}$ so as to establish " $\mathrm{O}<\mathrm{S}$ " order. For this reason, any subsequent scrambling of

30 Ko (personal communication) notes that this example is slightly awkward as a matrix question, for unclear reasons, but improves when embedded under a verb such as anta 'know'.

31 In this section, we discuss only subjects which are external arguments. Miyagawa (1989) observed that the subject of passive and unaccusative constructions behaves like an object with respect to quantifier stranding, an unsurprising observation in the context of Ko's proposals, as she discusses. 
the subject that would yield " $\mathrm{S}<\mathrm{O}$ " order is blocked as an ordering contradiction. This consequence is, of course, simply an instance of the Inverse Holmberg Effect in (39), with the scrambled object playing the role of the Icelandic quantified expression, and the subject playing the role of the verb.

Given that a quantifier and its associated nominal start out as sisters, (44) is excluded because its linearization imposes conflicting requirements on the derivation. For the object to precede the subject floated quantifier, it must scramble above the subject before $\mathrm{vP}$ is spelled out. In this position, however, it will not only precede the subject's quantifier, but will also precede the rest of the subject phrase. The nominal part of the subject might then be separated from its quantifier by leftward scrambling - but this instance of movement yields an Ordering Contradiction. Having established (when $v \mathrm{P}$ was spelled out) that the object precedes this material, later movement cannot reverse that order. $^{32}$

Ko provides many additional examples of this effect. Among many other things, she shows that her analysis predicts a distinction between the effects on linearization of low and high adverbs. Low adverbs, by virtue of belonging to the $v \mathrm{P}$ Spell-out domain, pattern with objects in blocking stranding of a subject quantifier. High adverbs, as we have seen in (46), do not. Ko provides evidence for this generalization from a wide variety of adverbs. Her discussion thus demonstrates (internal to Korean) the same point that we have already stressed in comparing Korean quantifier stranding to Icelandic QM: that it is not the details of specific structures and operations that yield Holmberg and Inverse Holmberg effects, but the consequences of these structures and operations for linearization.

32 It is necessary to assume that the external argument in Korean, having been merged as Spec, $v \mathrm{P}$, may not merge a second time to $v \mathrm{P}$ after object scrambling, thus establishing " $\mathrm{S}<\mathrm{O}$ " order within the lower Spell-out domain, despite the object scrambling. Ko notes that the impossibility of $v \mathrm{P}$-internal external-argument scrambling of this sort follows from Chomsky's proposal that probe-goal relations (a precursor to movement) are established under c-command. (The head $v$ does not c-command its specifiers.) Likewise, for our account of QM to be complete, we must ensure that the main verb in Icelandic cannot adjoin to its own maximal projection after QM has moved a quantified expression to its specifier. 


\section{Conclusions}

The final sections of this paper bring into relief the central argument for our architecture: the fact that a heterogeneous set of syntactic constructions appear to be constrained by a single factor - the avoidance of ordering contradiction. The choice seems to be between a heterogeneous set of syntactic constraints (directly reflecting the heterogeneity of the data) or a homogeneous account in terms of the communication between syntax and phonology.

If our proposal is correct, the overall picture of syntax itself is simpler. For example, there is no need to seek a syntax-internal account of constraints on subject scrambling in Korean, nor an account of the variety of elements that block (and fail to block) Object Shift in Scandinavian.

On the other hand, certain effects continue to arise from the inner workings of syntax itself. For example, if our proposal is right, it is phonology that blocks overt long-distance wh-movement unless it proceeds successive-cyclically via the left edge of Spell-out domains. Our proposals say nothing in themselves, however, about the circumstances under which movement to these left-edge positions is allowed or prohibited. If, for example, movement to Spec, $\mathrm{CP}$ occurs only when triggered by the presence on $\mathrm{C}$ of a particular feature, then the absence of such a feature will create an ordering contradiction - but one should not look to our system for an explanation of the absence of the relevant feature.

This observation, of course, raises interesting questions about the overall division of labor between syntax and phonology. Our proposals provide some new ways of investigating such questions. For example, if we are correct, one can distinguish constraints on movement that are "syntax-internal" from those that reflect properties of Linearization by looking for environments where problems for Linearization might be overcome by other instances of movement (or by processes such as ellipsis). In this paper, we focused on cases in which multiple instances of movement eliminate problems for linearization. In Fox and Pesetsky (in prep.), we extend the discussion to consider ellipsis as well - an investigation with further implications for a variety of constructions. 


\section{Appendix}

Our presentation has been informal. In the fuller version of this material, we sketch in greater detail how this approach might be formalized. This involves a choice among various possibilities, and we attempt to justify our choice on the basis of several empirical and conceptual considerations. Though space does not permit us to cover this material here, it may be useful nonetheless to present the rudiments of the implementation that we end up with. We do so, with a minimum of commentary, in this Appendix.

When a domain is spelled out, there is an Ordering Table that contains the output of any previous applications of Spellout. Spellout adds new ordering statements to the Ordering Table.

Laws of Precedence: The new ordering statements will be determined by Laws of Precedence: ${ }^{33}$

\section{(47) Format for the Laws of Precedence}

Where $\mathrm{X}$ is the mother of $\alpha$ and $\beta$; and $\alpha$ has properties $\varphi$ (e.g. is a head, complement, specifier, etc.); and $\beta$ has properties $\varphi^{\prime}, \alpha$ precedes $\beta$.

\section{(48) Some Possible Laws of Precedence for English}

a. Where $X$ is the mother of $\alpha$ and $\beta$ and $\alpha$ is a specifier of $\beta, \alpha$ precedes $\beta$.

b. Where $X$ is the mother of $\alpha$ and $\beta$ and $\beta$ is a complement of $\alpha$, $\alpha$ precedes $\beta$.

Movement: We assume that Movement is a "remerge" operation (Blevins (1990); Chomsky (2001a); Epstein et al. (1998); among others) rather than a copying procedure. The consequence of movement is the merger to $\mathrm{X}$ of a single element $\alpha$ previously merged to $\mathrm{Y}$.

33 We are agnostic as to the balance between language-specific and UG-determined aspects of these Laws; e.g. whether UG encompasses a "Head Parameter" Travis $(1984,1991)$ or not (Haider (1992); Kayne (1994)). 
This view is helpful to us for the following reasons. If movement of a constituent $\alpha$ with phonological properties $\mathrm{P}$ is viewed as a process that produces a copy of $\alpha$ and merges the copy in a new position, then the grammar must include some statement that prevents one of the two copies from being pronounced, i.e. that prevents $\mathrm{P}$ from being copied along with the other properties of $\alpha$. Various proposals have been offered that have this effect (see Groat and O'Neil (1996); Pesetsky (1998); Fox and Nissenbaum (1999); Bošković (2001); Bobaljik (2002); Landau (2003); among others). On the other hand, if we view movement as a process that takes a single instance of $\alpha$ and remerges it, the issue of multiple realizations of $\mathrm{P}$ does not arise (since nothing has been copied). Furthermore, the notion that an ordering contradiction might arise from movement makes better sense under a "remerge" view than under a "copy" view. Under a copy view, it is not obvious why " $\alpha<\beta$ " and " $\beta<\operatorname{copy}(\alpha)$ " should necessarily produce a problem for Spell-out. In contrast, under the remerge view, the contradiction is selfevident.

The fact that "traces do not count" is now a fact about what counts as the mother of a moved constituent, at least as far as ordering is concerned:

\section{(49) Mother}

The mother of $\alpha$ is the constituent formed by the most recent Merge of $\alpha$.

(50) Dominates (transitive closure of "mother")

A node $\mathrm{X}$ dominates $\alpha$ iff

(i) $\mathrm{X}$ is the mother of $\alpha$; or

(ii) $\mathrm{X}$ is the mother of $\beta$ and $\beta$ dominates $\alpha$.

Spellout: Spellout of a domain K consists of the following two steps:

1. The precedence relations that are given by relevant Laws of Precedence are gathered into a set $\mathrm{LP}(\mathrm{K})$.

2. An operation Linearize maps $\mathrm{LP}(\mathrm{K})$ into a set $\mathrm{L}(\mathrm{K})$, which contains ordering statements for terminal elements of $\mathrm{K}$, and adds $\mathrm{L}(\mathrm{K})$ to the Ordering Table. 
(51) Ordering statements provided by Laws of Precedence $\mathrm{LP}(\mathrm{X}):=$

$\{\alpha<\beta: \alpha$ and $\beta$ are dominated by $X$;

$\alpha$ precedes $\beta$ by a Law of Precedence;

and neither $\alpha$ nor $\beta$ is dominated by a Spell-out Domain other than $\mathrm{X}$ \}

(52) Linearize

(i) Form the Linearization $\operatorname{Set} \mathrm{L}(\mathrm{K}):=$ $\left\{\alpha^{\prime}<\beta^{\prime}: \alpha<\beta \in \operatorname{LP}(\mathrm{K})\right.$, and $\alpha^{\prime}$ is an End of $\alpha$ and

$\beta^{\prime}$ is a Beginning of $\beta$.

(ii) Update the Ordering Table by adding the members of $\mathrm{L}(\mathrm{K})$ [that is, Ordering-Table $\rightarrow$ (Ordering-Table $\cup \mathrm{L}(\mathrm{K}))$ ].

In Fox and Pesetsky (in prep.), we argue for the particular technical notion of "End" and "Beginning" (terms mentioned in (52)) given below in (53).

\section{(53) End and Beginning}

(i) $x$ is an End of $\alpha$ iff

$x$ is a terminal element reflexively dominated by $\alpha$ and

$\neg \exists y$ s.t. $y$ is dominated by $\alpha$ and $x<y \in$ Ordering Table. ${ }^{34}$

(ii) $x$ is a Beginning of $\alpha$ iff

$x$ is a terminal element reflexively dominated by $\alpha$ and

$\neg \exists y$ s.t. $y$ is dominated by $\alpha$ and $y<x \in$ Ordering Table.

The choice of these particular notions is dictated by a consideration of the degree of redundancy that is allowed to exist in the Ordering Table. Intuitively, an "End of $\alpha$ " according to (53) is a constituent that (at a given point in the derivation) still has a chance of being the last thing pronounced in $\alpha$. We reserve for the fuller presentation a comparison of this view with other natural notions of End and Beginning.

\section{Massachusetts Institute of Technology fox@mit.edu,pesetsk@mit.edu}

\footnotetext{
34 "Reflexively dominates" is the union of "dominates" and identity. If lexical items always dominate subcomponents (e.g. dog dominates its phonological segments), then we can eliminate the word reflexively here, since it will be the $/ \mathrm{d} /$ or $/ \mathrm{g} /$ of $d o g$ that counts as the beginning or end of the lexical item.
} 


\section{References}

Anagnostopoulou, E. (2003). The Syntax of Ditransitives: Evidence from Clitics. Berlin, New York: Mouton de Gruyter.

Barss, A. (1986). Chains and Anaphoric Dependence: On Reconstruction and Its Implications, Massachusetts Institute of Technology: Doctoral Dissertation.

Blevins, J. (1990). Syntactic Complexity: Evidence for Discontinuity and Multidomination, University of Massachusetts at Amherst: Doctoral dissertation.

Bobaljik, J. (1994). What Does Adjacency Do? In: Harley, H. \& Phillips, C. (eds.) The Morphology-Syntax Connection (pp. 1-32). MIT.

-(1995). Morphosyntax: The Syntax of Verbal Inflection, Massachusetts Institute of Technology: Doctoral Dissertation.

- (2002). A-Chains at the PF-Interface: Copies and 'Covert' Movement. Natural Language and Linguistic Theory, 20, 197-267.

Bošković, Ž. (2001). On the Nature of the Syntax-Phonology Interface: Cliticization and Related Phenomena. Oxford: Elsevier Science.

Chomsky, N. (1972). Some Empirical Issues in the Theory of Transformational Grammar. In: Peters, P. S. (ed.) Goals of Linguistic Theory. Englewood Cliffs, NJ: PrenticeHall.

- (1973). Conditions on Transformations. In: Anderson, S. \& Kiparsky, P. (eds.) $A$ Festschrift for Morris Halle (pp. 232-286). New York: Holt Rinehart \& Winston.

- (1993). A Minimalist Program for Linguistic Theory. In: Hale, K. \& Keyser, J. (eds.) The View from Building 20 (pp. 1-52). Cambridge, Mass.: MIT Press.

- (2000). Minimalist Inquiries. In: Martin, R., Michaels, D. \& Uriagereka, J. (eds.) Step by Step: Essays on Minimalist Syntax in Honor of Howard Lasnik (pp. 89-156). Cambridge, Mass.: MIT Press.

-(2001a). Derivation by Phase. In: Kenstowicz, M. (ed.) Ken Hale: A Life in Language (pp. 1-52). Cambridge, Mass.: MIT Press.

-(2001b). Beyond Explanatory Adequacy. Cambridge, Mass.: MIT Working Papers in Linguistics.

Christensen, K. K. (1986). Norwegian Ingen: A Case of Post-Syntactic Lexicalization. In: Östen, D. \& Holmberg, A. (eds.) Workshop at the Ninth Scandinavian Conference (pp. 21-35). Stockholm: University of Stockholm.

- (1995). Quantifier-Movement and Its Syntactic Reflexes. Ms., University of Bergen.

Den Besten, H. (1983). On the Interaction of Root Transformations and Lexical Deletive Rules. In: Abraham, W. (ed.) On the Formal Syntax of the Westgermania. Amsterdam: John Benjamins.

Epstein, S. D., Groat, E. M., Kawashima, R. \& Kitahara, H. (1998). A Derivational Approach to Syntactic Relations. Oxford: Oxford University Press.

Fox, D. (1999). Reconstruction, Binding Theory, and the Interpretation of Chains. Linguistic Inquiry, 30, 157-196.

Fox, D. \& Lasnik, H. (2003). Successive Cyclic Movement and Island Repair: The Difference between Sluicing and VP Ellipsis. Linguistic Inquiry, 34, 143-154.

Fox, D. \& Nissenbaum, J. (1999). Extraposition and Scope: A Case for Overt QR. In: Proceedings of the West Coast Conference on Formal Linguistics 18 (pp. 132-144). Somerville, MA: Casadilla Press.

Fox, D. \& Pesetsky, D. (in prep.). Cyclic Linearization and the Typology of Movement. 
Fujita, N. (1994). On the Nature of Modification: A Study of Floating Quantifiers and Related Constructions, University of Rochester.: PhD.

Fukui, N. \& Takano, Y. (1998). Symmetry in Syntax: Merge and Demerge. Journal of East Asian Linguistics, 7, 27-86.

Gračanin, M. (2004). V-N Compounds in Italian and Croatian. Ms., MIT.

Groat, E. \& O'Neil, J. (1996). Spell-out at the LF Interface. In: Abraham, W., Epstein, S. D., Thráinsson, H. \& Zwart, C. J.-W. (eds.) Minimal Ideas (pp. 113-139). Amsterdam: John Benjamins Publishing Company.

Haider, H. (1992). Branching and Discharge. vol. 23. Working Papers of the SF13 340. University of Stuttgart.

Haig, J. H. (1980). Some Observations on Quantifier Float in Japanese. Linguistics, 18, $1065-1083$.

Hale, K. L. \& Keyser, S. J. (1993). On Argument Structure and the Lexical Expression of Syntactic Relations. In: Hale, K. \& Keyser, S. J. (eds.) The View from Building 20 (pp. 53-110). Cambridge, Mass.: MIT Press.

- (2002). Prolegomenon to a Theory of Argument Structure. Cambridge, Mass.: MIT Press.

Holmberg, A. (1986). Word Order and Syntactic Features, Stockholm: Doctoral Dissertation.

- (1998). Remarks on Holmberg's Generalization. Studia Linguistica, 53, 1-39.

Iatridou, S. \& Kroch, A. (1992). The Licensing of CP-Recursion and Its Relevance to the Germanic Verb-Second Phenomenon. Working Papers in Scandinavian Syntax, 50, $1-24$.

Johnson, K. \& Vikner, S. (1994). The Position of the Verb in Scandinavian Infinitives: In V or C but Not in I. Working Papers in Scandinavian Syntax, 53, 61-84.

Jónsson, J. G. (1996). Clausal Architecture and Case in Icelandic, Linguistics, University of Massachusetts: Doctoral Dissertation.

Kathol, A. (2000). Linear Syntax. Oxford: Oxford University Press.

Kayne, R. S. (1994). The Antisymmetry of Syntax. Cambridge, Mass.: MIT Press.

Ko, H. (2003). Asymmetry in Scrambling and Cyclic Spell-Out. Paper presented at Approaching Asymmetry at the Interface Conference, Université du Québec à Montréal.

- (2004). Asymmetries in Scrambling and Cyclic Linearization. Ms., MIT.

Kuroda, S.-Y. (1983). What Can Japanese Say About Government and Binding. In: Barlow, M. (ed.) Proceedings of the West Coast Conference on Formal Linguistics (pp. 153-164). Stanford: Stanford Linguistics Association.

Landau, I. (2003). Modular Recoverability: Chain Resolution in Hebrew V(P)-Fronting. Ms., Ben Gurion University.

Lasnik, H. (2001). When Can You Save a Structure by Destroying It? Paper presented at Proceedings of the North East Linguistic Society, Georgetown University.

Lebeaux, D. (1991). Relative Clauses, Licensing, and the Nature of the Derivation. In: Rothstein, S. D. (ed.) Perspectives on Phrase Structure: Heads and Licensing. San Diego: Academic Press.

Matushansky, O. (to appear). Head Movement in Linguistic Theory. In: Sabbagh, J. \& Hiraiwa, K. (eds.) MIT Working Papers in Linguistics. Cambridge, Mass.: MIT.

McCloskey, J. (2000). Quantifier Float and Wh-Movement in an Irish English. Linguistic Inquiry, 31, 57-84.

McDaniel, D. (1989). Partial and Multiple Wh-Movement. Natural Language \& Linguistic Theory, 7, 565-604. 
Merchant, J. (to appear). Variable Island Repair under Ellipsis. In: Johnson, K. (ed.) Topics in Ellipsis. Cambridge, UK: Cambridge University Press.

Miyagawa, S. (1989). Structure and Case Marking in Japanese. San Diego: Academic Press.

Müller, G. (2000). Shape Conservation and Remnant Movement. Paper presented at Proceedings of the North East Linguistic Society, Rutgers University.

Nilsen, Ø. (2003). Eliminating Positions: Syntax and Semantics of Sentence Modification, University of Utrecht: Doctoral dissertation.

Nissenbaum, J. (2000). Investigations of Covert Phrase Movement, Linguistics, Massachusetts Institute of Technology: Doctoral Dissertation.

Perlmutter, D. (1972). Evidence for Shadow Pronouns in French Relativization. In: Peranteau, P. M., Levi, J. N. \& Phares, G. C. (eds.) The Chicago Which Hunt: Papers from the Relative Clause Festival, April 13, 1972. Chicago: Chicago Linguistic Society.

Pesetsky, D. (1998). Some Optimality Principles of Sentence Pronunciation. In: Barbosa, P., Fox, D., Hagstrom, P., McGinnis, M. \& Pesetsky, D. (eds.) Is the Best Good Enough? (pp. 337-384). Cambridge, Mass.: MIT Press.

Pesetsky, D. \& Torrego, E. (2004). Tense, Case, and the Nature of Syntactic Categories. In: Guéron, J. \& Lecarme, J. (eds.) The Syntax of Time. Cambridge, Mass.: MIT Press.

Rögnvaldsson, E. (1987). On Word Order in Icelandic. In: Proceedings of the Seventh Biennial Conference of Teachers of Scandinavian Studies in Great Britain and Northern Ireland (pp. 33-49). London: University College London.

Ross, J. R. (1969). Guess Who? In: Binnick, R., Davison, A., Green, G. and Morgan, J. (eds.) Papers from the Fifth Regional Meeting of the Chicago Linguistic Society. Chicago: University of Chicago.

Sabbagh, J. (2003). Ordering and Linearizing Rightward Movement. Ms., MIT.

Saito, M. (1985). Some Asymmetries in Japanese and Their Theoretical Implications, Massachusetts Institute of Technology: Doctoral Dissertation.

Sells, P. (2001). Structure, Alignment and Optimality in Swedish. Stanford, CA: CSLI Publications.

Sigurđsson, H. Á. (1989). Verbal Syntax and Case in Icelandic, University of Lund: Doctoral Dissertation.

Svenonius, P. (2000). Quantifier Movement in Icelandic. In: P. Svenonius (ed.) The Derivation of $V O$ and $O V$. Amsterdam: John Benjamins.

Takahashi, S. (2004). Pseudo-Gapping and Cyclic Linearization. In: Moulton, K. and Wolf, M. (eds.) Proceedings of the North East Linguistic Society 34.

Toyoshima, T. (2001). Head-to-Spec Movement. In: Alexandrova, G. M. \& Arnaudova, O. (eds.) The Minimalist Parameter: Selected Papers from the Open Linguistics Forum, Ottawa, 12-23 March 1997. Amsterdam: John Benjamins.

Travis, L. D. (1984). Parameters and Effects of Word Order Variation, Massachusetts Institute of Technology: Doctoral Dissertation.

- (1991). Parameters of Phrase Structure and Verb-Second Phenomena. In: Freidin, R. (ed.) Principles and Parameters in Comparative Grammar (pp. 339-364). Cambridge, Mass.: MIT Press.

Uriagereka, J. (1999). Multiple Spell-Out. In: Epstein, S. \& Hornstein, N. (eds.) Working Minimalism (pp. 251-282). Cambridge, Mass.: MIT Press.

Williams, E. (2003). Representation Theory. Cambridge, Mass.: MIT Press.

Zwart, C. J.-W. (1996). Morphosyntax of Verb Movement: A Minimalist Approach to the Syntax of Dutch. vol. 39. Dordrecht: Kluwer. 
